\title{
Design, Analysis, Fabrication, and Testing of a Novel Piezoelectric Pump
}

\section{October 2003}

Prepared by

J. F. Jansen

R. F. Lind

J. B. Chesser

L. J. Love 


\title{
DOCUMENT AVAILABILITY
}

Reports produced after January 1, 1996, are generally available free via the U.S. Department of Energy (DOE) Information Bridge:

Web site: http://www.osti.gov/bridge

Reports produced before January 1, 1996, may be purchased by members of the public from the following source:

\author{
National Technical Information Service \\ 5285 Port Royal Road \\ Springfield, VA 22161 \\ Telephone: 703-605-6000 (1-800-553-6847) \\ TDD: 703-487-4639 \\ Fax: 703-605-6900 \\ E-mail: info@ntis.fedworld.gov \\ Web site: http://www.ntis.gov/support/ordernowabout.htm
}

Reports are available to DOE employees, DOE contractors, Energy Technology Data Exchange (ETDE) representatives, and International Nuclear Information System (INIS) representatives from the following source:

Office of Scientific and Technical Information

P.O. Box 62

Oak Ridge, TN 37831

Telephone: 865-576-8401

Fax: 865-576-5728

E-mail: reports@adonis.osti.gov

Web site: http://www.osti.gov/contact.html

This report was prepared as an account of work sponsored by an agency of the United States Government. Neither the United States government nor any agency thereof, nor any of their employees, makes any warranty, express or implied, or assumes any legal liability or responsibility for the accuracy, completeness, or usefulness of any information, apparatus, product, or process disclosed, or represents that its use would not infringe privately owned rights. Reference herein to any specific commercial product, process, or service by trade name, trademark, manufacturer, or otherwise, does not necessarily constitute or imply its endorsement, recommendation, or favoring by the United States Government or any agency thereof. The views and opinions of authors expressed herein do not necessarily state or reflect those of the United States Government or any agency thereof. 
ORNL-2003/188

DESIGN, ANALYSIS, FABRICATION, AND TESTING OF A NOVEL PIEZOELECTRIC PUMP

J. F. Jansen, R. F. Lind, J. B. Chesser, and L. J. Love

Date Published: October 2003

\author{
Prepared by \\ OAK RIDGE NATIONAL LABORATORY \\ P.O. Box 2008 \\ Oak Ridge, Tennessee 37831-6285 \\ managed by \\ UT-Battelle, LLC \\ for the \\ U.S. DEPARTMENT OF ENERGY \\ under contract DE-AC05-00OR22725
}





\section{CONTENTS}

Page

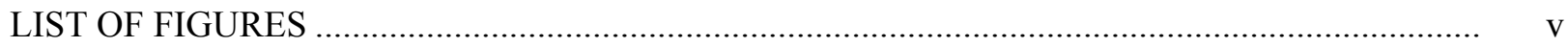

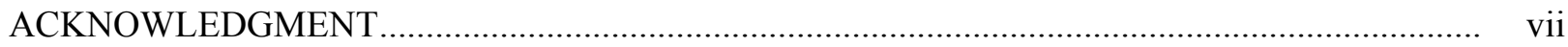

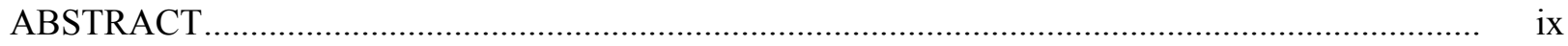

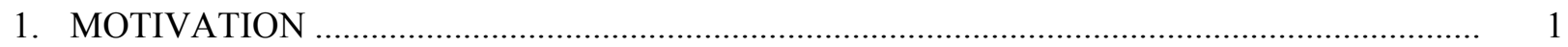

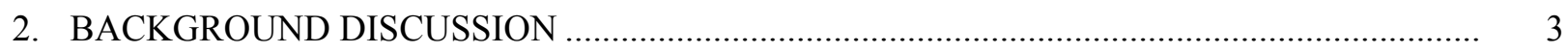

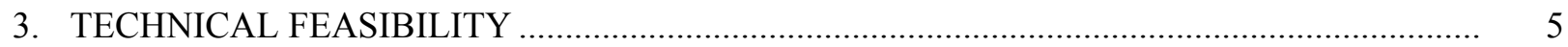

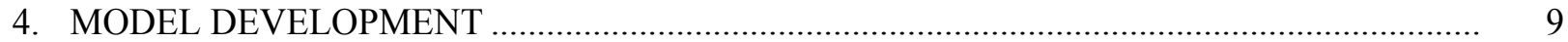

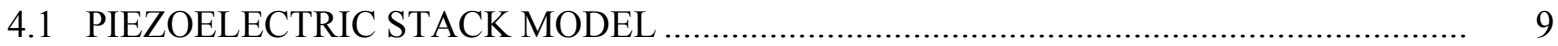

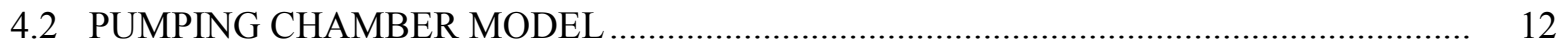

4.3 CHAMBER AND STRUCTURAL MEMBER MODEL ................................................. 13

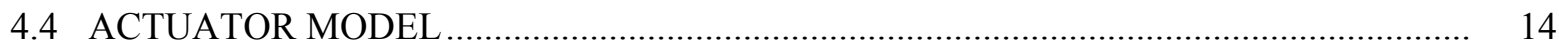

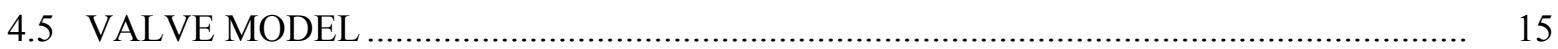

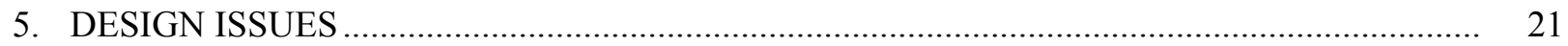

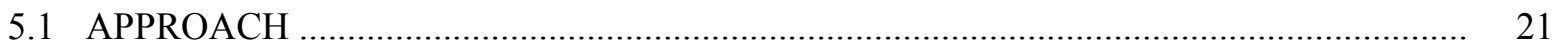

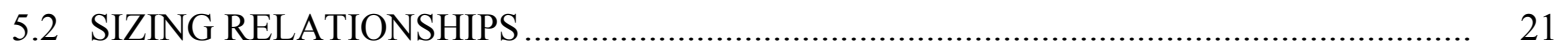

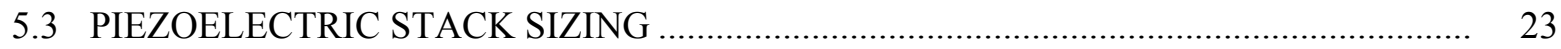

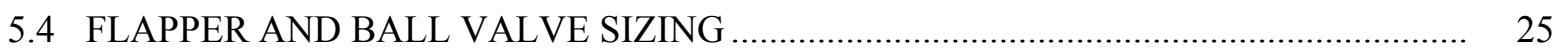

5.5 CHAMBER AND PISTON SIZING …............................................................... 25

5.5.1 General Design Considerations............................................................ 25

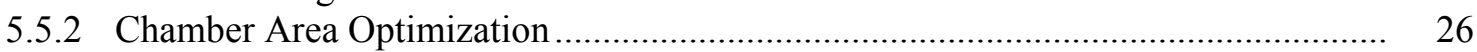

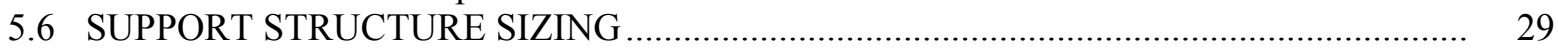

5.7 OVERVIEW DRAWINGS OF FINAL DESIGN ........................................................... 29

6. PERFORMANCE MEASUREMENT OF PUMP COMPONENTS AND PUMP ....................... 37

6.1. RESONANT FREQUENCY VERIFICATION ............................................................... 37

6.2 STACK POLARIZATION IMPACT ON POWER ELECTRONICS .................................. 40

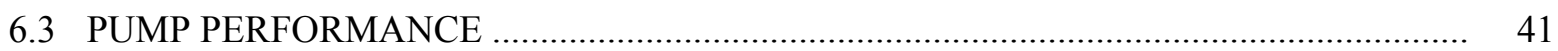

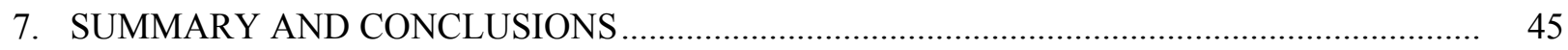

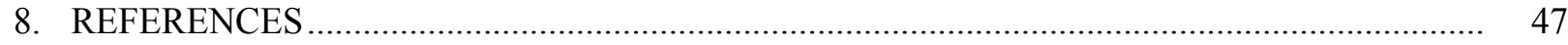

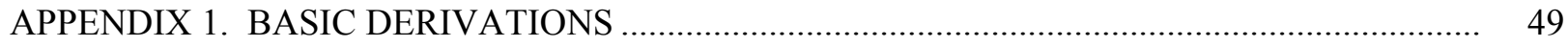

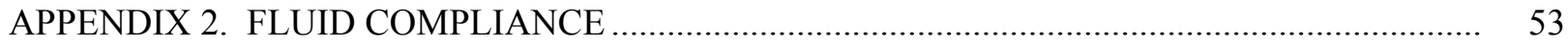




\section{LIST OF FIGURES}

Figure

Page

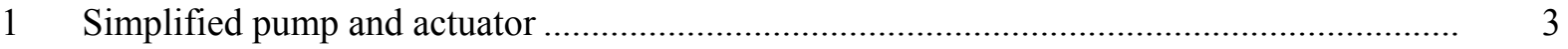

2 Electromechanical model of piezoelectric actuator with mechanical load........................... 5

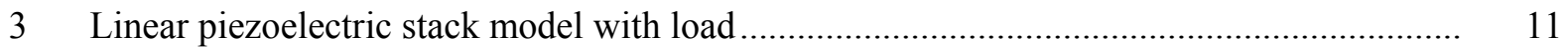

$4 \quad$ Linear piezoelectric stack model with load and stack losses ............................................. 11

$5 \quad$ Linear piezoelectric stack model showing output velocity $\left(\mathrm{v}_{\mathrm{t}}\right)$ and applied force $\left(\mathrm{F}_{\mathrm{p}}\right) \ldots . \quad 11$

$6 \quad$ Pumping chamber where the two vertical arrows denote fluid flow .................................. 12

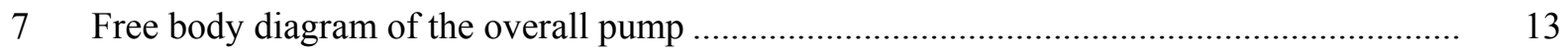

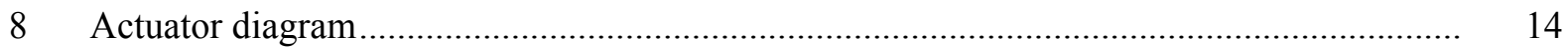

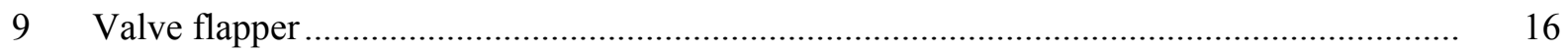

10 Dynamic model of valve flapper, hole, and oriface ….................................................. 16

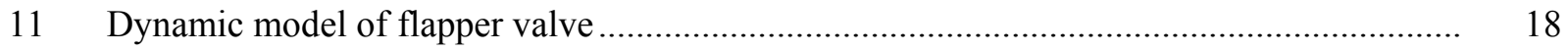

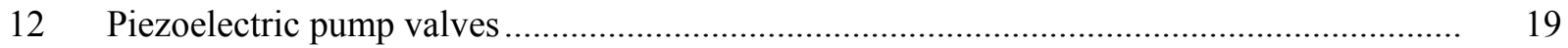

13 Electromechanical model of piezoelectric stack and mechanical load................................. 21

14 Flow vs. pressure for 0.003 in thickness for flapper ....................................................... 25

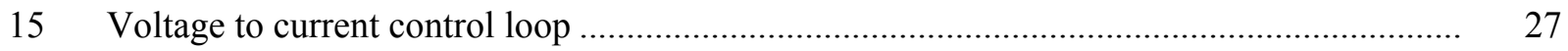

16a Power out as a function of area and operating frequency for $300 \mathrm{psi}$ load .......................... 28

16b Power out as a function of area and operating frequency for $600 \mathrm{psi}$ load .......................... 28

$16 \mathrm{c}$ Power out as a function of area and operating frequency for $100 \mathrm{psi}$ load .......................... 29

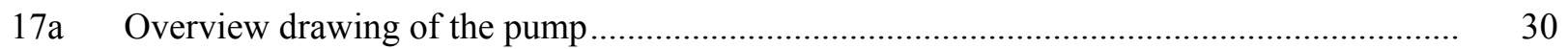

17b Detail assembly drawing and corresponding components .......................................... 31

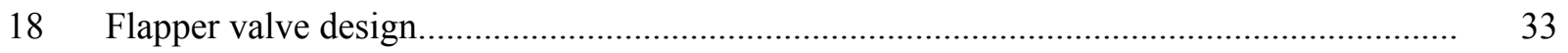

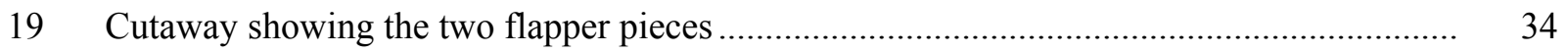

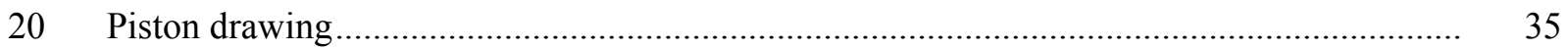




\section{LIST OF FIGURES (cont'd)}

$\begin{array}{ll}\text { Figure } & \text { Page }\end{array}$

21a Experimental setup to determine flapper valve natural frequency ..................................... 37

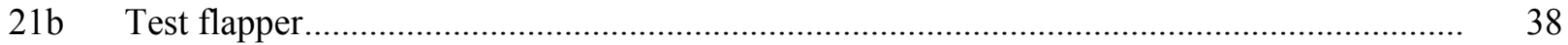

22 Flapper with thickness $=0.003$ in., resonate fundamental frequency approximately $2 \mathrm{kHz} . . \quad 39$

$23 \quad$ Flapper with thickness $=0.007$ in., resonate frequency approximately $3.3 \mathrm{kHz} \ldots \ldots \ldots \ldots \ldots \ldots . . . . . . . . .39$

$24 \quad$ Flapper with thickness $=0.0095$ in., resonate frequency approximately $5 \mathrm{kHz} \ldots \ldots \ldots \ldots \ldots \ldots \ldots . . . . . . . .40$

25 No load input capacitance as a function of frequency .......................................................

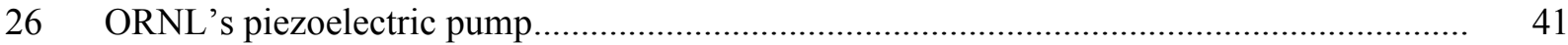

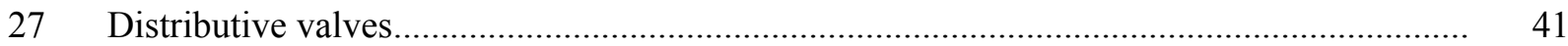

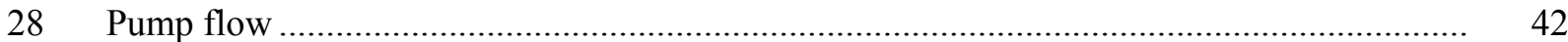

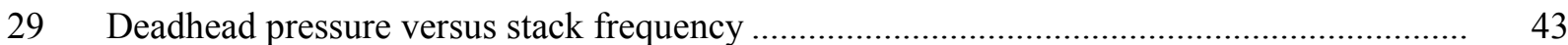

30 Power out of the piezoelectric pump for load of $650 \mathrm{psi}$ and reservoir pressure of $50 \mathrm{psi} \ldots . . \quad 43$

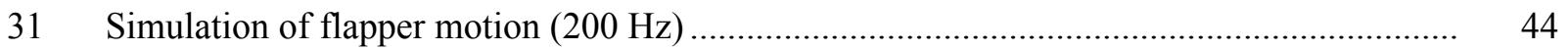

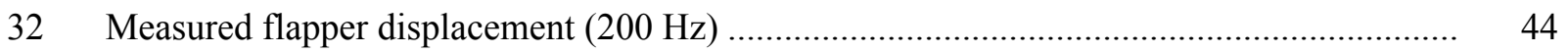

A1-1 Electromechanical model of piezoelectric stack and mechanical load.............................. 49 


\section{ACKNOWLEDGMENT}

The authors gratefully acknowledge the support by the U.S. DOE Office of Biological and Environmental Research Environmental Management Sciences Program and the Defense Science Office through the Exoskeletons for Human Augmentation Program with specific appreciation to the Program Manager Dr. John Main. The authors also wish to express their appreciation to Ms. Karen Harber for her work in editing and formatting the finalized text and appreciation to both Mr. Brad Richardson and Mr. Pete Lloyd for their editorial and technical reviews. 


\begin{abstract}
While there is a wide range of actuation technologies, none currently rivals the overall performance (power density, bandwidth, stress, stroke) of conventional hydraulic actuation. It is well known in the actuation community that the power-to-weight ratios and the power-to-volume ratios of hydraulic actuators are, respectively, around 5 times and 10 to 20 times larger than comparable electric motors. Due to fundamental limitations in the magnetic flux density in the supporting structures and limitations in the heat transfer out of electric actuators, significant changes in these ratios are not likely in the near future. Thermal limitations associated with electric motors do no apply to hydraulic actuators since the hydraulic fluid cools and lubricates the system. Hydraulic actuators are capable of holding a load without any energy expenditure, resilient to high impact loads, and typically do no need a transmission system. However, with all of these virtues, hydraulic actuators have serious practical implementation problems. Typically, hydraulic actuators have moderate to poor reliability when compared to electric actuators, leaky (at least in reputation), poor energy efficiencies and poor controllability due to either overlapping or underlapping in the spool of the control valves. This work addresses a new type of electric actuator that attempts to combine the best of both the electric and hydraulic mediums. Easy controllability as with electric actuators, scalability, and high power densities associated with hydraulics were the goals of this work.
\end{abstract}




\section{MOTIVATION}

The goal of this work is to expand upon a novel actuator that has been developed at Oak Ridge National Laboratory (ORNL) that has the potential to make single crystal materials a driving source for a new type of hydraulic actuator. The goal of this new actuator is to exceed the current level of power and volume density of electric motors to a value similar to conventional hydraulics. Currently, the power-toweight ratios of hydraulic actuators are around 5 times and the power-to-volume ratios are 10 to 20 times that of comparable electric motors (Hollerbach, 1992). One difficulty of using piezoelectric material pertains to converting small displacements to large motion (i.e., transmission problem). One approach is the inch-worm, where micro-stepping action through rapid lock-and-move sort of motion are used to create a large linear motion. Another concept is that of a piezoelectric hydraulic pump (Nasser, 2000), where small quantities of fluid move at very high frequencies. The accumulation of small drops of fluid at a high rate adds up to a large flow rate. Both of these concepts are based on the idea of cyclic motion of the piezoelectric material. The second approach of moving one drop of fluid at a time is the approach being taken in this research effort and has the potential of achieving the radical improvement in motion control for a high-power density actuator. Based on ORNL's previous work in this area, we have constructed an experimental piezoelectric pumping system that feeds a conventional hydraulic actuator allowing us to explore the fundamental science associated with this effort and verifying the potential concept.

Alternatives to hydraulic actuators presently do not exist due to the high power-to-weight densities required. As a comparison, electric motors are roughly 5 to 10 times lower in power densities. Ideally, one would like an actuator that had the power density of current hydraulic actuators, had the cleanliness of an electric motor, low cost (including control elements), low maintenance, encouraged modular construction (i.e., a family of actuators with appropriate sensors, controller, and power modulation like a servo valve and could be designed as a single module), generated no mixed waste, energy efficient, and highly controllable. From a systems integration perspective, the proposed actuator would appear functionally as an electric motor (i.e., only electrical wires would have to be connected to the power electronics with no fluid lines); but would have a radically smaller packaging volume and weight compared to a conventional electric motor. Attempting to achieve such characteristics is the essence of this work. Investigation into a new type of electric actuator that combines the best of both the electric and hydraulic mediums is the basic concept. The power density would be similar to hydraulic actuators and therefore no power train would be required as would be needed for any electric motor. Precision control would be possible since small drops of fluids are incrementally controlled during each pump cycle. Because of the direct control of hydraulic fluid through the pump and the lack of a power train, true modularity in remote system design would be possible. Finally, significant weight reduction and higher energy efficiency would enhance the mission longevity of any remote application. 


\section{BACKGROUND DISCUSSION}

Large forces and small displacements occur in a piezoelectric crystal when an electric field is applied. Compressive stress levels can be as high as $35 \mathrm{MPa}$ (5000 psi), whereas the tensile stress levels can be only 5 to $10 \%$ of the compressive stress level. Typically, a mechanical force bias is required to avoid the tensile stress limits. Displacements are typically very small for piezoelectric materials. One difficulty of using piezoelectric material pertains to converting small displacements to large motion (i.e., the transmission problem). One concept that potentially overcomes this limitation is that of a piezoelectric hydraulic pump (Nassor, 2000), where small quantities of fluid (i.e., liquid) move at very high frequencies. The accumulation of small drops of fluid at a high rate adds up to a large flow rate. This latter approach of moving one drop of fluid at a time is the one being taken in this research and will be the main focus of this work (see Fig. 1).

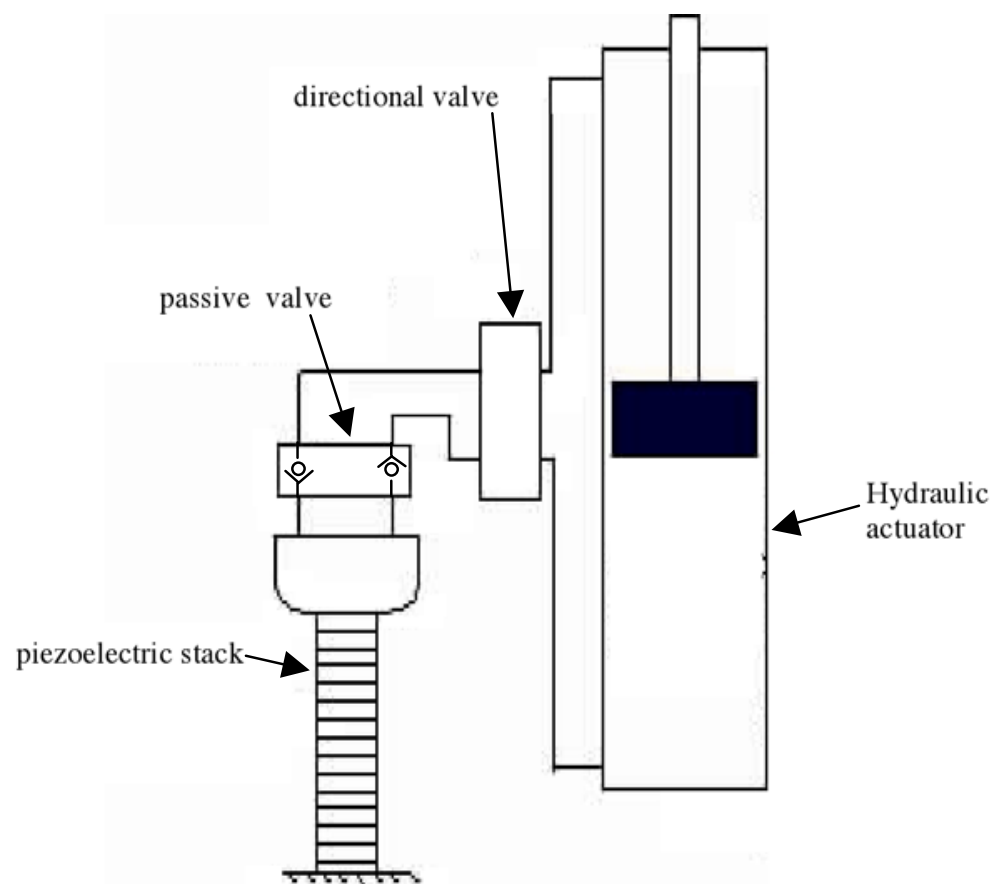

Fig. 1. Simplified pump and actuator.

(Note: the pump could possibly be placed inside the actuator.) 


\section{TECHNICAL FEASIBILITY}

Before the technical design details are laid out, an initial feasibility study of the underlying physics of the proposed actuator will be presented. A mechanical drawing of the basic pump is shown in Fig. 1. Note that eventually the pump will be placed inside the actuator making the overall system self-contained and thereby significantly minimizing fluid leakage. Next, if one examines the equivalent linear electrical model of the piezoelectric actuator with a mechanical load as shown in Fig. 2, the piezoelectric has a shunt and a series capacitor in its equivalent model. The left side is the electrical port where a voltage is applied and current is injected into the crystal. The right-side port is where force is represented by an equivalent voltage potential and velocity is represented by electrical current flow. A mechanical load, $Z_{m}$, is shown attached to the mechanical port (i.e., it could represent a simple mass load or an arbitrary load).

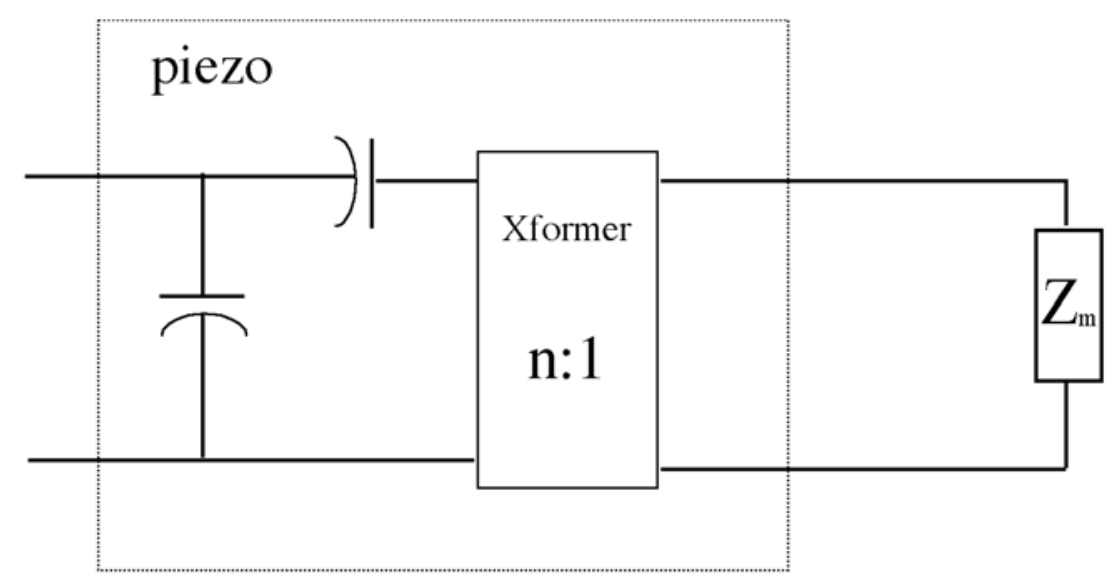

Fig. 2. Electromechanical model of piezoelectric actuator with mechanical load.

If the mechanical load can be represented as a purely resistive-like load that has been optimized to achieve maximum power transfer at a given frequency, f, then it can be shown (see Appendix 1) that the maximum power per volume of the piezoelectric actuator can be approximated to

$$
\frac{\text { power }}{\text { volume }}=\frac{\pi}{8} \mathrm{k}^{2} \mathrm{f}\left(\frac{1}{2} \varepsilon_{33}^{\mathrm{T}} \mathrm{E}^{2}\right),
$$

where

$$
\begin{array}{ll}
\mathrm{E} & =\text { electric field, typically under } 10^{6} \mathrm{~V} / \mathrm{m}, \\
\varepsilon_{33}^{\mathrm{T}} & =\text { electric permittivity, } \\
\mathrm{f} & =\text { frequency of voltage source }(\mathrm{Hz}), \text { and } \\
\mathrm{k}^{2} & =\text { electrical to mechanical conversion constant }(0.86 \text { for PZN). }
\end{array}
$$

The term in the parentheses in Eq. (1) is the electrical energy density stored in the piezoelectric material, and for modest electric fields this term could have values of $0.02 \mathrm{~J} / \mathrm{cm}^{3}$ (or $2.7 \mathrm{~J} / \mathrm{kg}$ for a typical density value of $8200 \mathrm{~kg} / \mathrm{m}^{3}$ ) for the single-crystal piezoelectric material PZN-PT. Larger energy-storage terms have been reported in the literature, but because of fatigue life limitations (recall that due to the transmission problem, billions of cycles will be required from this material), this reduced value is more reasonable. Power-to-volume for electric motors around the $1 \mathrm{~kW}$ level is approximately $1.3 \mathrm{~W} / \mathrm{cm}^{3}$. To 
obtain a factor of 5 times this value and therefore rival that of hydraulic actuators, the cyclic frequency, $f$, would have to be around $1 \mathrm{kHz}$ based on Eq. (1).

Utilizing a $1 \mathrm{kHz}$ operating frequency and based on the results in Appendix 1, an ideal piezoelectric stack with length of 3 inches and a cross-sectional area of $1 \mathrm{in}^{2}$ is examined for a single crystal PZN-PT material operating a perfect pumping chamber. Single crystal was chosen because of its potentially superior performance (Park, 1997). Optimality is defined as the maximum power transfer that the stack could exert in compression based on sinusoidal operating conditions. Results are summarized in Table 1.

Table 1. Preliminary analysis of piezoelectric pump utilizing PZN-PT material

\begin{tabular}{|c|c|}
\hline Values at maximum power transfer & Single-crystal material \\
\hline Peak pressure & $1,700 \mathrm{psi}$ \\
\hline Average flow & $0.4 \mathrm{gpm}$ \\
\hline Power & $320 \mathrm{~W}$ \\
\hline Strain & $0.2 \%$ \\
\hline Stroke & $6 \mathrm{e}-3$ in. $(152 \mu \mathrm{m})$ \\
\hline Power/Weight & $800 \mathrm{~W} / \mathrm{kg}$ \\
\hline Power/Volume & $7 \mathrm{~W} / \mathrm{cm}^{3}$ \\
\hline
\end{tabular}

A number of points can be made concerning this table. First, the optimal pressure of 1700 psi is within the pressure ranges of conventional hydraulic power systems and no transmission system will be required. Next the strain magnitude is within bounds for this material. Power-to-volume for frameless electric motors around the $1 \mathrm{~kW}$ level is approximately $1.3 \mathrm{~W} / \mathrm{cm}^{3}$, which is over 5 times smaller than the single crystal materials. The power-to-weight for an electric motor at the $1 \mathrm{~kW}$ level is approximately $300 \mathrm{~W} / \mathrm{kg}$, which is about a factor of 2.5 smaller than the single crystal material. If one takes into consideration that electric motors are high-speed, low-torque devices, and that some sort of transmission system would be required to connect an electric motor to a hydraulic pump, the power-to-weight ratio of a packaged electric motor with a transmission system (i.e., a gear box) would be much lower than $300 \mathrm{~W} / \mathrm{kg}$ (more like 100 to $150 \mathrm{~W} / \mathrm{kg}$ ). The piezoelectric material would have power densities in both weight and volume that are 5 times larger than those for conventional electric motors because no transmission system would be required.

A number of mechanical design issues such as stroke dimensions, fluid compressibility, and valving will now be addressed. Whereas, all of the values previously mentioned are exceptional, the stroke dimension is a critical number in the determination of construction feasibility for two major reasons. First, fluid particle contaminates can readily exceed $25 \mu \mathrm{m}$ in size with standard filtration techniques. Second, dimensions under a thousandths of an inch are difficult to machine (e.g., temperature variations). Since the stroke displacement is $152 \mu \mathrm{m}$ (as shown in the above table), fluid particle contaminates and machining will not be a problem. Fluid contamination of conventional electro-hydraulic servo valves must be maintained below $5 \mu \mathrm{m}$. The proposed piezoelectric pump has an order-of-magnitude greater tolerance to fluid contamination. Next, the issue of fluid compressibility will be addressed. The question 
is how much of the stroke of the pump is required to compress the fluid assuming the system pressure of say 2000 psi (2000 psi value was picked as an example) is applied. Assuming a stroke length of $75 \mu \mathrm{m}$ and a typical fluid bulk modulus of 100,000 psi, only $1.5 \mu \mathrm{m}$ out of $75 \mu \mathrm{m}$ of the stroke is required to compress the fluid (see Appendix 2 for details). Under normal operating conditions, fluid compression should not be a significant problem. Lastly, there are two approaches for the valves shown in Fig. 1 that have to operate around $1 \mathrm{kHz}$ to rival the power density of a hydraulic actuator. Either passive or active valving could be utilized. Passive valving means that the pressures that are created within the pumping chamber and the actuator will activate the valve. Active valving denotes that some other power source would be utilized to initiate opening and closing of the valve. In this work, only passive valving will be examined due to the tremendous compactness advantages it offers in the overall design. To achieve passive valving that can respond to $1 \mathrm{kHz}$, small distributive mini-valves (see Fig. 27) would have to be designed instead of one large one for each of the inlet and outlet flow directions so that the effective mass of each valve is small. As an example, assume that 30 mini-valves for each inlet and outlet flow directions are distributed around the circumference of the pumping chamber. As indicated in Appendix 2, it appears that the natural frequency of each inlet check ball and outlet check ball is over $2.2 \mathrm{kHz}$ which exceeds the $1 \mathrm{kHz}$ operating frequency by over a factor of 2 . In summary, a distributive passive valving scheme appears to hold promise for a compact passive valve design.

While the mechanical approach appears to be promising, the next question relates to the issue of suitable electronics to control the electrical power into the PZN-PT crystal. Typical piezoelectric actuators are driven by a high-voltage power source of around 400 to $1000 \mathrm{~V}$. The size of the drive electronics often exceeds the overall packaging volume of the actuator by an order-of-magnitude. However, for the proposed pump there are a number of favorable factors. First, the trajectory of the piezoelectric actuator is periodic and therefore we can fix the frequency to a value in the low $\mathrm{kHz}$ range. With simple amplitude modulation, the flow out of the pump could easily be controlled and has been demonstrated at ORNL. If one puts a series inductor with the same magnitude of impedance as the combined impedance of the combined shunt and series capacitance at the operating frequency, it should be possible to resonate the electrical elements in the piezoelectric stack (note: this is not a mechanical but a electrical resonance) and generate a significant voltage boost. Due to the obvious advantage of resonating the series and shunt capacitors, a series-resonate type power inverter (Kazimierczuk, 1995) topology could play a significant role in reducing the overall power electronics packaging. Finally, ferroelectric materials such as PZN-PT have significant amounts of hysteresis that can seriously degrade tracking performance (around 20\%). Hysteresis is caused by the nonlinear relationship between the material polarization and the applied electric field created by the voltage source. Two common techniques around this problem have been to replace the voltage source with a charge source (Newcomb, 1982) or apply positional or velocity feedback (Main, 1997 and Newton, 1996). Both of these methods can significantly reduce the hysteresis effect. 


\section{MODEL DEVELOPMENT}

\subsection{PIEZOELECTRIC STACK MODEL}

The approach taken by this researcher is to start off with the linear model of the piezoelectric stack with the intention of adding the nonlinear models of the load and modifying the linear models where appropriate later. One of the most widely used descriptions of the linear constitutive relations for the piezoelectric ceramic behavior has been published by the Institute of Electrical and Electronics Engineers (IEEE, 1987). There are many different models describing the piezoelectric ceramic behavior; however, models fall into two categories: those that are based on a voltage-proportional constitutive relationship and those that are based on a charge-proportional constitutive relationship (Goldfarb, 1997). The form that will be taken by this researcher is to formulate these relationships such that current (or charge) and mechanical force are the input variables and the mechanical velocity and displacement are the output variables. These constitutive relations are typically expressed in a tensor formulation as:

$$
\mathrm{S}_{\mathrm{p}}=\mathrm{s}_{\mathrm{pq}}^{\mathrm{E}} \mathrm{T}_{\mathrm{q}}+\mathrm{d}_{\mathrm{kp}} \mathrm{E}_{\mathrm{k}}
$$

and

$$
\mathrm{D}_{\mathrm{i}}=\mathrm{d}_{\mathrm{iq}} \mathrm{T}_{\mathrm{q}}+\varepsilon_{\mathrm{ik}}^{\mathrm{T}} \mathrm{E}_{\mathrm{k}}
$$

where $\mathrm{S}$ represents the strain tensor, $\mathrm{s}^{\mathrm{E}}$ is the elastic compliance matrix constrained to a constant electric field, T represents the stress tensor, $d$ is the matrix of piezoelectric material coefficients, and $\varepsilon^{T}$ is the permittivity matrix constrained to a constant stress. For the material used in this study, all the stresses and fields are limited to the 3-direction and the constitutive relationship can be accurately approximated by

$$
\mathrm{S}_{3}=\mathrm{s}_{33}^{\mathrm{E}} \mathrm{T}_{\mathrm{q}}+\mathrm{d}_{33} \mathrm{E}_{\mathrm{k}}
$$

and

$$
\mathrm{D}_{3}=\mathrm{d}_{33} \mathrm{~T}_{3}+\varepsilon_{33}^{\mathrm{T}} \mathrm{E}_{3}
$$

where the $\mathrm{s}_{33}^{\mathrm{E}}, \mathrm{d}_{33}, \varepsilon_{33}^{\mathrm{T}}$ are now all scalars. Let $\mathrm{S}_{3}=\mathrm{x} / \mathrm{t}, \mathrm{D}_{3}=\mathrm{Q} / \mathrm{A}, \mathrm{E}_{3}=\mathrm{V} / \mathrm{t}, \mathrm{T}_{3}=\mathrm{F} / \mathrm{A}$ where $\mathrm{x}$ is the displacement of a single stack, $t$ is the thickness of a single stack, $\mathrm{Q}$ is the charge on a single stack, $\mathrm{V}$ is the voltage on a stack, $\mathrm{F}$ is the applied load, $\mathrm{A}$ is the stack cross-sectional area. Define the total displacement of $\mathrm{N}$ stack in series as $\mathrm{x}_{\mathrm{T}}=\mathrm{N} \mathrm{x}$ and define a load force, $\mathrm{F}$, as $\mathrm{F}=-\mathrm{Z}_{\mathrm{m}} \dot{\mathrm{x}}_{\mathrm{T}}-\mathrm{F}_{\mathrm{s}}$ where $\mathrm{Z}_{\mathrm{m}}$ is a passive load impedance and $\mathrm{F}_{\mathrm{s}}$ is an external force.

Using Eq. (4) and the previous definitions, Eq. (4) is equivalent to

$$
\frac{\mathrm{x}}{\mathrm{t}}=\mathrm{s}_{33}^{\mathrm{E}} \frac{\mathrm{F}}{\mathrm{A}}+\mathrm{d}_{33} \frac{\mathrm{V}}{\mathrm{t}}=\mathrm{s}_{33}^{\mathrm{E}} \frac{\left(-\mathrm{Z}_{\mathrm{m}} \dot{\mathrm{x}}_{\mathrm{T}}-\mathrm{F}_{\mathrm{s}}\right)}{\mathrm{A}}+\mathrm{d}_{33} \frac{\mathrm{V}}{\mathrm{t}} \text {, }
$$

which after a few algebraic manipulations and utilizing the Laplace s-operator for derivatives (assuming zero initial conditions), collect like terms of $\mathrm{x}$ and Eq. (6) become 


$$
\mathrm{x}=-\frac{\mathrm{t}}{\mathrm{A}} \mathrm{s}_{33}^{\mathrm{E}}\left(1+\mathrm{ts}_{33}^{\mathrm{E}} \frac{\mathrm{Z}_{\mathrm{m}}}{\mathrm{A}} \mathrm{Ns}\right)^{-1} \mathrm{~F}_{\mathrm{s}}+\mathrm{d}_{33}\left(1+\mathrm{ts}_{33}^{\mathrm{E}} \frac{\mathrm{Z}_{\mathrm{m}}}{\mathrm{A}} \mathrm{Ns}\right)^{-1} \mathrm{~V}
$$

From Eq. (5) and the previous definitions,

$$
\frac{\mathrm{Q}}{\mathrm{A}}=\mathrm{d}_{33} \frac{\mathrm{F}}{\mathrm{A}}+\varepsilon_{33}^{\mathrm{T}} \frac{\mathrm{V}}{\mathrm{t}}=-\frac{\mathrm{d}_{33}}{\mathrm{~A}}\left(\mathrm{Z}_{\mathrm{m}} \mathrm{Nsx}+\mathrm{F}_{\mathrm{s}}\right)+\varepsilon_{33}^{\mathrm{T}} \frac{\mathrm{V}}{\mathrm{t}}
$$

Inserting Eq. (7) into Eq. (8) to remove the variable $x$ and defining the total charge $Q_{t}=N Q$, one obtains

$$
\mathrm{Q}_{\mathrm{t}}=-\mathrm{Nd}_{33} \frac{\mathrm{F}_{\mathrm{s}}}{1+\mathrm{ts}_{33}^{\mathrm{E}} \frac{\mathrm{Z}_{\mathrm{m}}}{\mathrm{A}} \mathrm{Ns}}+\frac{\mathrm{NA}}{\mathrm{t}}\left[\left(\varepsilon_{33}^{\mathrm{T}}-\frac{\mathrm{d}_{33}^{2}}{\mathrm{~s}_{33}^{\mathrm{E}}}\right)+\frac{\frac{\mathrm{d}_{33}^{2}}{\mathrm{~s}_{33}^{\mathrm{E}}}}{1+\mathrm{ts}_{33}^{\mathrm{E}} \frac{\mathrm{Z}_{\mathrm{m}}}{\mathrm{A}} \mathrm{Ns}}\right] \mathrm{V}
$$

The above expression can be cast in terms of current and with a slight rearrangement of terms

$$
I_{t}=s Q_{t}=\frac{N A}{t}\left(\varepsilon_{33}^{T}-\frac{d_{33}^{2}}{s_{33}^{E}}\right) s V+\frac{\left(\frac{N A}{t} \frac{d_{33}^{2}}{s_{33}^{E}}\right) s V}{1+\left(\frac{N A}{t} \frac{d_{33}^{2}}{s_{33}^{E}}\right)\left(\frac{t_{33}^{E}}{A d_{33}}\right)^{2} Z_{m} s}-\frac{\left(\frac{N A}{t} \frac{d_{33}^{2}}{s_{33}^{E}}\right)\left(\frac{t_{33}^{E}}{A_{33}^{E}}\right) F_{s}}{1+\left(\frac{N A}{t} \frac{d_{33}^{2}}{s_{33}^{E}}\right)\left(\frac{t_{33}^{E}}{A_{33}^{E}}\right)^{2} Z_{m} s}
$$

or in a more condensed form as

$$
I_{t}=s C_{1} V+\frac{s C_{2}\left(V-T^{\prime} F_{s}\right)}{1+s C_{2} T^{\prime 2} Z_{m}}
$$

where

$$
\begin{gathered}
\mathrm{C}_{0}=\frac{\mathrm{NA}}{\mathrm{t}} \varepsilon_{33}^{\mathrm{T}}, \\
\mathrm{C}_{1}=\mathrm{C}_{0}\left(1-\mathrm{k}^{2}\right), \\
\mathrm{C}_{2}=\mathrm{C}_{0} \mathrm{k}^{2}, \\
\mathrm{k}^{2}=\frac{\mathrm{d}_{33}^{2}}{\varepsilon_{33}^{\mathrm{T}} \mathrm{s}_{33}^{\mathrm{E}}},
\end{gathered}
$$

and 


$$
\mathrm{T}^{\prime}=\frac{\mathrm{t} \mathrm{s}_{33}^{\mathrm{E}}}{\mathrm{Ad}_{33}}
$$

Equation (11) has an equivalent linear circuit representation as shown in Fig. 3 where $C_{1}$ and $C_{2}$ terms represent capacitive elements, $\mathrm{T}^{\prime}$ is the turns ratio of a transformer that links the electrical model on the left port to the mechanical model on the right port of the transformer.

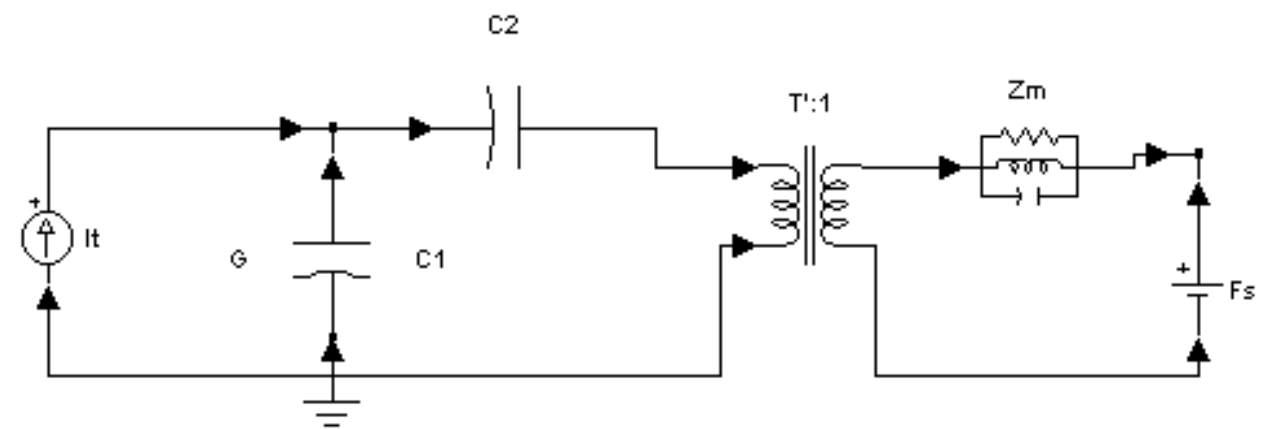

Fig. 3. Linear piezoelectric stack model with load.

To accommodate for stack losses (not load losses), a resistive element $G_{1}$ is added in shunt across $C_{1}$ as shown in Fig. 4.

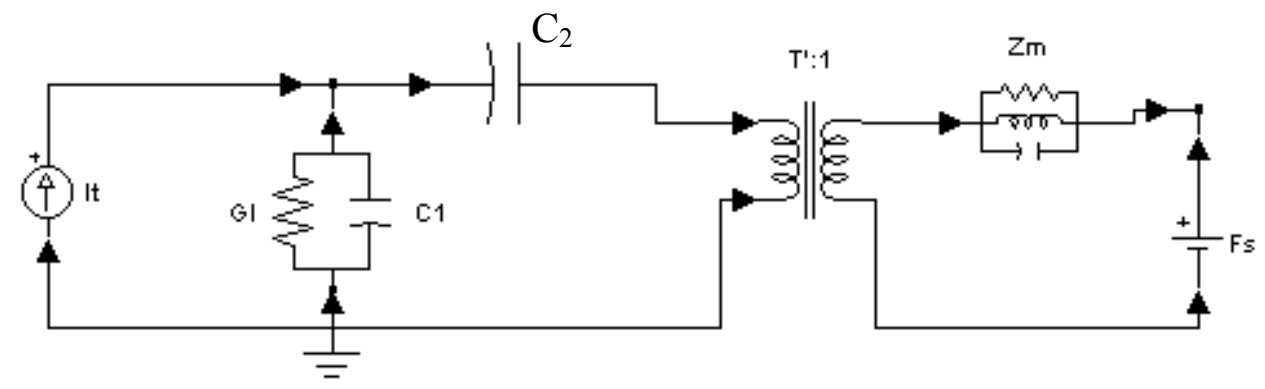

Fig. 4. Linear piezoelectric stack model with load and stack losses.

For the computer model, the piezoelectric stack (Fig. 5) will be modeled as

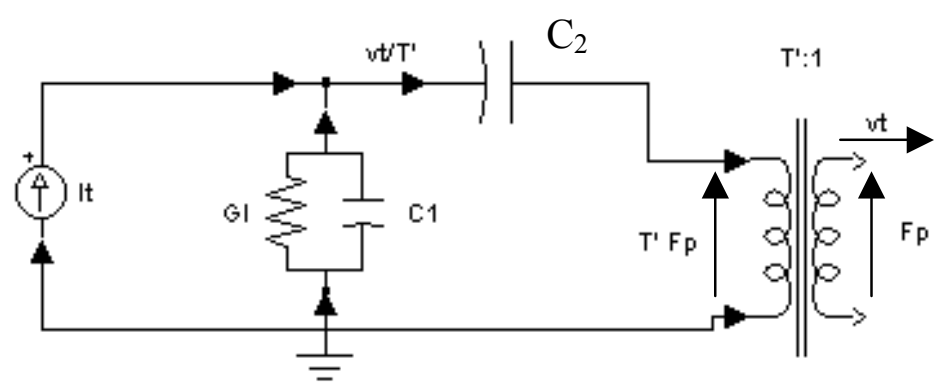

Fig. 5. Linear piezoelectric stack model showing output velocity $\left(v_{t}\right)$ and applied force $\left(F_{p}\right)$. 
The state-space representation of the circuit in Fig. 5 is simply

$$
\frac{d}{d x}\left[\begin{array}{c}
v \\
F_{p}
\end{array}\right]=\left[\begin{array}{cc}
\frac{1}{C_{1}} & \frac{-1}{C_{1}} \\
\frac{1}{C_{1} T^{\prime}} & \frac{-1}{T^{\prime}}\left(\frac{1}{C_{1}}+\frac{1}{C_{2}}\right)
\end{array}\right]\left[\begin{array}{c}
i_{t}-v^{-} G_{1} \\
\frac{v_{t}}{T^{\prime}}
\end{array}\right]
$$

where $\mathrm{v}$ is the voltage across capacitor $\mathrm{C}_{1}$. If a voltage source instead of a current source is the driving source, then to avoid violation of causality, a LR-series impedance should be connected between the source and the piezoelectric stack.

\subsection{PUMPING CHAMBER MODEL}

An idealized pumping chamber is shown in Fig. 6.

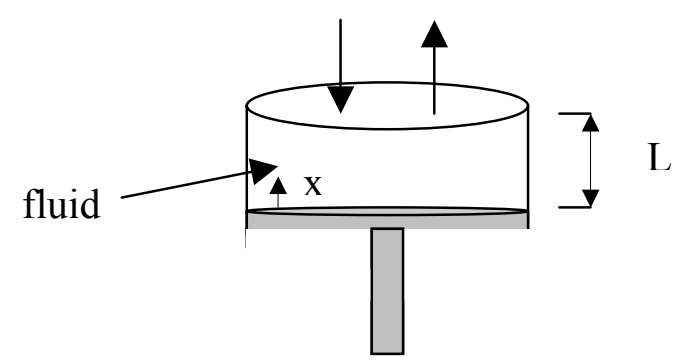

Fig. 6. Pumping chamber where the two vertical arrows denote fluid flow.

The pumping area is A and assuming that the outlet and inlet ports are closed (i.e., the chamber is deadheaded). By the definition of the fluid bulk modulus,

$$
\beta=\frac{-\mathrm{V}_{0}}{\Delta \mathrm{V}} \Delta \mathrm{P}
$$

which can be manipulated through the following steps to arrive at the equivalent chamber stiffness, $\mathrm{K}_{\mathrm{f}}$ :

$$
\begin{gathered}
\Delta \mathrm{V}=-\mathrm{A} \Delta \mathrm{x}=\frac{-\mathrm{V}_{0}}{\beta} \Delta \mathrm{P}, \\
-\mathrm{A} \Delta \mathrm{x}=\frac{-\mathrm{L}}{\beta} \Delta \mathrm{F}, \\
\frac{\beta \mathrm{A}}{\mathrm{L}} \Delta \mathrm{x}=\Delta \mathrm{F}
\end{gathered}
$$

and

$$
\mathrm{K}_{\mathrm{f}} \Delta \mathrm{x}=\Delta \mathrm{F}
$$


When the fluid chamber is deadheaded, the fluid looks like a simple spring of stiffness $K_{f}=\beta A / L$. The equivalent capacitance of the chamber transferred to the left of the transformer and can be can be shown to be equivalent to

$$
\mathrm{C}_{\mathrm{m}}^{\prime}=\frac{1}{\mathrm{~T}^{\prime 2} \mathrm{~K}_{\mathrm{f}}}
$$

Likewise mass would look like an inductor to the left of the transfer and can be calculated as

$$
\mathrm{L}_{\mathrm{m}}^{\prime}=\mathrm{T}^{\prime 2} \text { mass }
$$

\subsection{CHAMBER AND STRUCTURAL MEMBER MODEL}

The piezoelectric stack presses against the pumping chamber that is held in place by the structural body of the pump as shown in Fig. 7 below.

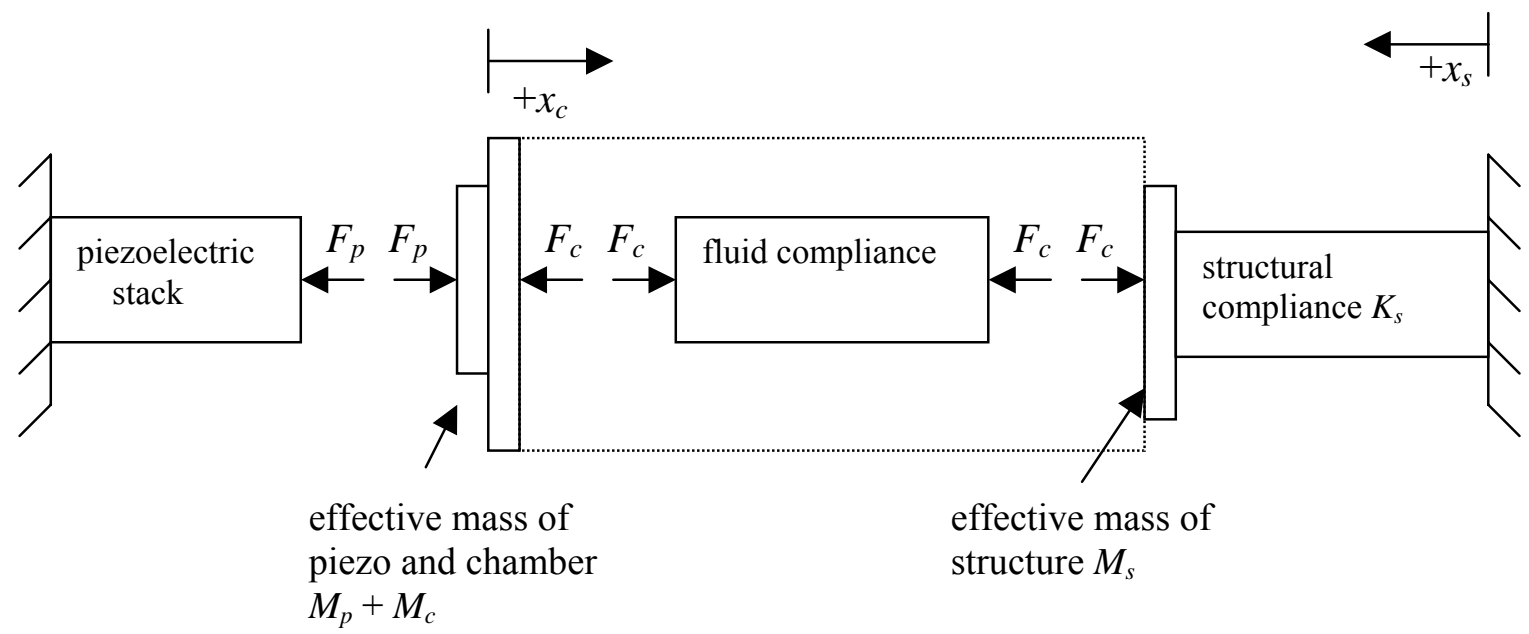

Fig. 7. Free body diagram of the overall pump.

Based on conservation of fluid, the pumping chamber can be described as

$$
\frac{\mathrm{V}_{\mathrm{c}}}{\beta} \frac{\mathrm{dP}_{\mathrm{c}}}{\mathrm{dx}}=\mathrm{A}_{\mathrm{c}}\left(\dot{\mathrm{x}}_{\mathrm{c}}+\dot{\mathrm{x}}_{\mathrm{s}}\right)+\mathrm{Q}_{\text {in }}-\mathrm{Q}_{\text {out }}-\mathrm{Q}_{\text {leakage }},
$$

where $\mathrm{V}_{\mathrm{c}}$ is the volume of the fluid chamber, $\mathrm{P}_{\mathrm{c}}$ is the chamber pressure and is equal to force applied to the chamber, $F_{c}$, divided by the area, $A_{c}$, of the chamber, $\beta$ is the fluid bulk modulus, $x_{c}$ and $x_{s}$ are the displacements of the respective ends of the chamber, $Q_{\text {in }}$ is the flow rate of the fluid coming into the chamber, $\mathrm{Q}_{\text {out }}$ is the fluid leaving the chamber, and $\mathrm{Q}_{\text {leakage }}$ is the any stray leakage flows.

Based on Newtonian mechanics, the chamber acceleration is proportional to the applied forces on the chamber, or 


$$
\left(\mathrm{M}_{\mathrm{c}}+\mathrm{M}_{\mathrm{p}}\right) \ddot{\mathrm{x}}_{\mathrm{c}}=\mathrm{F}_{\mathrm{p}}-\mathrm{F}_{\mathrm{c}}
$$

where the effective mass of the piezoelectric stack, $M_{p}$, is $1 / 3$ the total mass of the stack and $M_{c}$ is the mass of chamber piston. Due to the low frequency of operation (below $1 \mathrm{kHz}$ ), a lumped parameter model for the pumping chamber is adequate because the acoustical wavelength is much larger than the overall piezoelectric stack. Likewise, the structural compliance forces can be represented as

$$
\mathrm{M}_{\mathrm{s}} \ddot{\mathrm{x}}_{\mathrm{s}}+\mathrm{D}_{\mathrm{s}} \dot{\mathrm{x}}_{\mathrm{s}}+\mathrm{K}_{\mathrm{s}} \mathrm{x}_{\mathrm{s}}=-\mathrm{F}_{\mathrm{c}}
$$

and where $D_{s}$ is a structural damping term (not shown in Fig. 7), $K_{s}$ is the structural compliance, and $\mathrm{M}_{\mathrm{s}}$ is the effective mass of the structure.

\subsection{ACTUATOR MODEL}

The flow out of the pump will be fed to a hydraulic actuator as shown in Fig. 8.

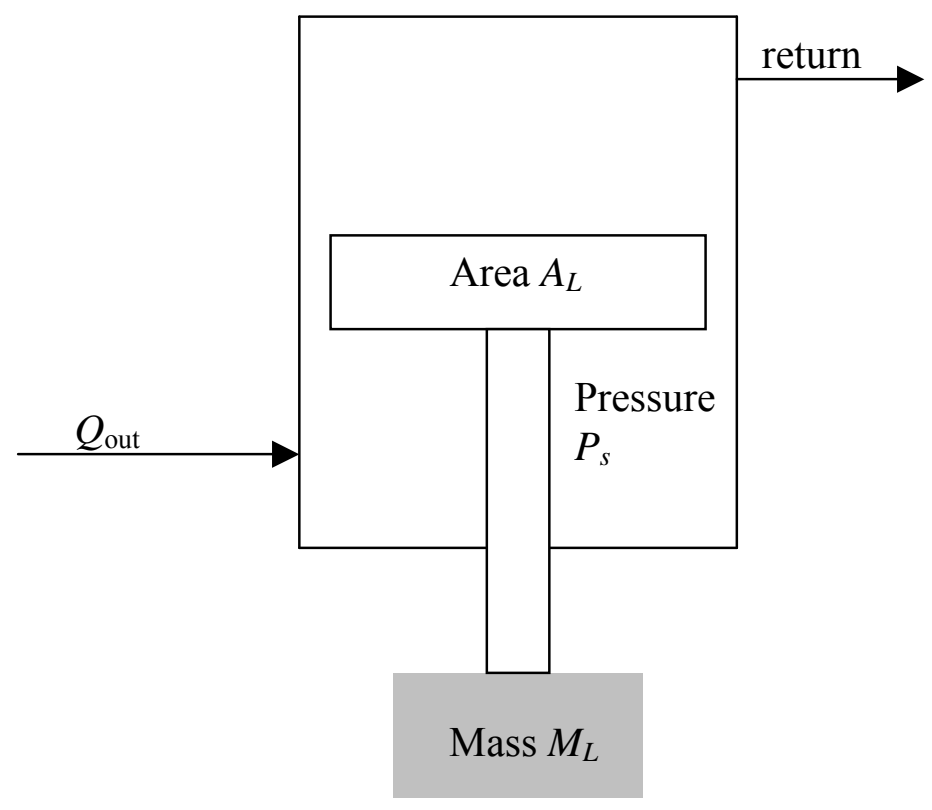

Fig. 8. Actuator diagram.

The actuator and load models are based on fluid conservation and Newtonion dynamics and are as follows:

$$
\mathrm{Q}_{\text {out }}=\frac{\mathrm{V}_{\mathrm{L}}}{\beta} \frac{\mathrm{dP}_{\mathrm{s}}}{\mathrm{dx}}+\mathrm{A}_{\mathrm{L}} \dot{\mathrm{x}}_{\mathrm{m}}
$$

and

$$
\mathrm{M}_{\mathrm{L}} \ddot{\mathrm{x}}_{\mathrm{m}}=\mathrm{A}_{\mathrm{L}} \mathrm{P}_{\mathrm{s}}-\mathrm{B}_{\mathrm{v}} \dot{\mathrm{x}}_{\mathrm{m}}-\mathrm{M}_{\mathrm{L}} \mathrm{g}
$$


where $V_{L}$ is the volume of the fluid in the actuator which varies as $V_{L}=V_{L 0}+A_{L} x_{m}$ where $x_{m}$ is the actuator postion and $V_{L 0}$ is the initial fluid volume, $M_{L}$ is the mass of the load, $g$ is the gravitational constant, $\mathrm{P}_{\mathrm{s}}$ is the actuator pressure, $\mathrm{B}_{v}$ is the fluid damping, and $\mathrm{A}_{\mathrm{L}}$ is the effective area of the cylinder.

\subsection{VALVE MODEL}

The last remaining model is for the valve. The aerodynamic force on any valve results from a pressure drop across the valve. Its precise calculation would require a detailed fluid dynamic analysis of the entire flow pattern and an integration of the resultant pressure distribution over the valve. Due to the difficult nature of the problem presented, an approximate calculation of the force can be made by assuming that the pressure is uniformly equal to chamber pressure up to the minimum restriction and uniformly equal to the actuator or return pressure beyond this point. While such an abrupt change in static pressure is physically unrealizable, the resulting force calculation is useful in design (see Anderson, 1967). The representatation of the force on a single valve element, $F_{v}$, will be represented as

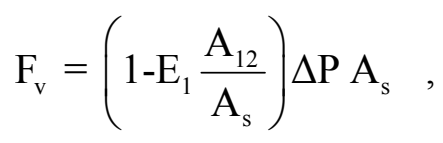

where $\mathrm{E}_{1}$ is a fixed constant (approximately close to 1 in value), $A_{s}$ is the seat area which will equal $\pi \mathrm{d}^{2} / 4$ where $\mathrm{d}$ is the diameter of the hole, $\mathrm{A}_{12}$ is the effective flow area, $\Delta \mathrm{P}$ is the pressures across the valve.

The poppet-like valve head will be mechanically pushed against the piston head by means of a cantilever beam. The equivalent spring constant $\mathrm{K}_{\mathrm{s}}$, which can be derived from standard beam deflection models, is

$$
\mathrm{K}_{\mathrm{s}}=\frac{\mathrm{E} \frac{\mathrm{t}^{3} \mathrm{~b}_{0}}{12}\left(1-\frac{\mathrm{b}_{1}}{\mathrm{~b}_{0}}\right)^{3}}{\mathrm{~L}^{3}\left[1.5\left(\frac{\mathrm{b}_{1}}{\mathrm{~b}_{0}}\right)^{2}-2\left(\frac{\mathrm{b}_{1}}{\mathrm{~b}_{0}}\right)+0.5+\left(\frac{\mathrm{b}_{1}}{\mathrm{~b}_{0}}\right)^{2} \log \frac{\mathrm{b}_{0}}{\mathrm{~b}_{1}}\right]}
$$

or

$$
\mathrm{K}_{\mathrm{s}}=\frac{\mathrm{EI}_{0} \mathrm{f}\left(\frac{\mathrm{b}_{1}}{\mathrm{~b}_{0}}\right)}{\mathrm{L}^{3}}
$$


where $b_{0}$ is the base width, $b_{1}$ is the tip width, $L$ is the beam length, $E$ is Young's Modulus, $t$ is the beam thickness, and $\mathrm{I}_{0}=\mathrm{b}_{0} \mathrm{t}^{3} / 12$ is the area moment about the widest section of the beam, and the function $\mathrm{f}$ is the algebraic component that is left from Eq. (31). Figure 9 shows the general flapper. The flapper is composed of two parts: a cantilever beam and a disk. The disk will be modeled as a point mass on top of the cantilever beam.

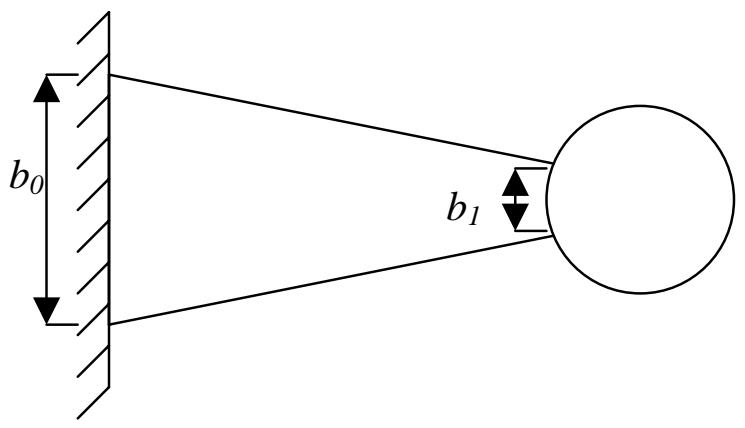

Fig. 9. Valve flapper.

Each valve segment can be modeled as a single compliant element modulating the flow through an oriface from a short pipe segment as shown in Fig. 10. With the assumption that the oriface is operating in the turbulent regime and the short pipe segment is operating in the laminar regime.

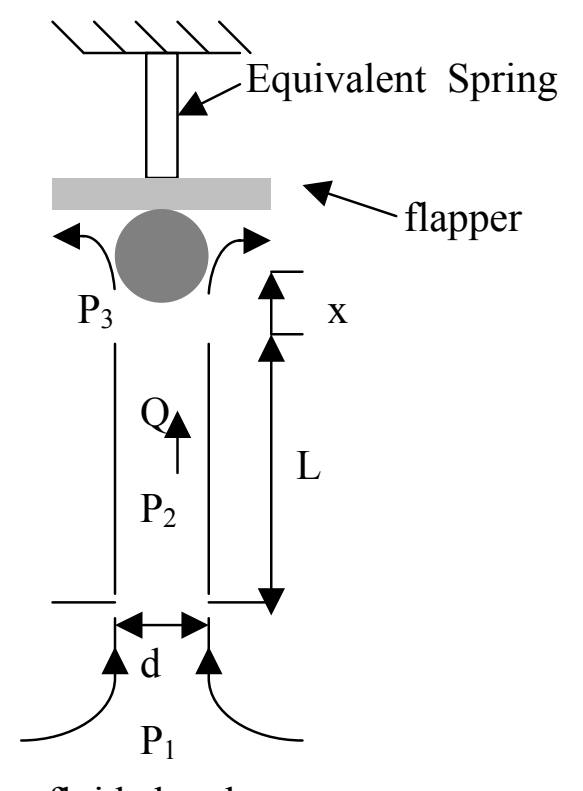

fluid chamber

Fig. 10. Dynamic model of valve flapper, hole, and oriface. 
Flapper length is 0.17 in, hole diameter is 0.071 in and the pipe length is 0.205 in, $b_{0}=0.05$ in, $\mathrm{b}_{1}=0.02 \mathrm{in}$, and the disk diameter is $0.08 \mathrm{in}$. The valve thickness will be varied from 0.003 to $0.009 \mathrm{in}$. The beam stiffness, Eqs. (31) and (32) can now be reformulated as

$$
\mathrm{K}_{\mathrm{s}} \cong \frac{2.5 \mathrm{EI}_{0}}{\mathrm{~L}^{3}}
$$

The natural frequency of the tapered beam is

$$
f_{1}=\frac{\lambda_{1}^{2}}{2 \pi L^{2}}\left(\frac{\mathrm{EI}_{0}}{\rho \mathrm{A}_{0}}\right)^{1 / 2} .
$$

where $\lambda_{1} \cong 2.1$ (from Figs. 9-18 on page 163 of Blevins), $I_{0}=$ area moment of inertia $=b_{0} t^{3} / 12$, $\mathrm{A}_{0}=$ cross sectional area at the widest point $=\mathrm{b}_{0} \mathrm{t}$, and $\mathrm{E}$ is the Young's Modulus of steel. Equation (34) can be shown to be equivalent to

$$
\mathrm{f}_{1} \cong \frac{1}{2 \pi}\left(\frac{\lambda_{1}^{4} \mathrm{EI}_{0}}{\left(\frac{2}{1+\frac{\mathrm{b}_{1}}{\mathrm{~b}_{0}}}\right) \mathrm{L}^{3} \mathrm{M}_{\text {beam }}}\right)^{1 / 2}
$$

where $\mathrm{M}_{\text {beam }}$ is the mass of the beam. To obtain an approximate estimate of the natural frequency of the cantilever beam including the mass of the disk, the beam stiffness divided by the equivalent mass of the beam plus the mass of the disk is approximately equal to the square of the angular frequency. By utilizing the stiffness of the beam (see Eq. (33)) and Table 8-8, page 159 of Blevins, and setting $b_{1} / b_{0}=0.4$, one obtains

$$
\mathrm{f}_{1} \cong \frac{1}{2 \pi}\left(\frac{2.5 \mathrm{EI}_{0}}{\mathrm{~L}^{3}\left(\mathrm{M}_{\text {disk }}+\frac{25}{7 \lambda_{1}^{4}} \mathrm{M}_{\text {beam }}\right)}\right)^{1 / 2}
$$

This gives a rough estimate of the natural frequency of the flapper of approximately $2 \mathrm{kHz}$ for $\mathrm{t}=0.003 \mathrm{in}, 4.6 \mathrm{kHz}$ for $0.007 \mathrm{in}$, and $6.2 \mathrm{kHz}$ for $\mathrm{t}=0.0095 \mathrm{in}$. It should be noted (see Merritt, 1967, page 320) the fluid could possible aid and increase the natural frequency. Section 6 shows some actual testing of flapper valves to verify the general validity of the above relationships. Also, the ball mass will be added to the mass of the disk term in Eq. (36). 
The relationship between the pressure and flow in the short pipe flow (Merrit, 1967) is

$$
\mathrm{P}_{1}-\mathrm{P}_{2}=\frac{128 \mu \mathrm{L}}{\pi \mathrm{d}^{4}} \mathrm{Q}
$$

where

$$
\mu=\text { absolute kinematic viscosity, } d \text { is the pipe diameter, and } L \text { is the pipe length. }
$$

The pressure flow relationship between the oriface and the valve is

$$
\mathrm{Q}=\mathrm{C}_{\mathrm{d}} \pi \mathrm{dx} \operatorname{sign}\left(\mathrm{P}_{2}-\mathrm{P}_{3}\right) \sqrt{\frac{2\left(\mathrm{P}_{2}-\mathrm{P}_{3}\right)}{\rho}}
$$

where $C_{d}$ is the discharge coefficient, $d$ is the pipe diameter, $x$ is the opening of the oriface, and $\rho$ is the fluid density. What one would like is to obtain a relationship between $\mathrm{Q}$ and $\mathrm{P}_{2}-\mathrm{P}_{3}$ given the pressure across the valve $\Delta \mathrm{P}=\left(\mathrm{P}_{1}-\mathrm{P}_{3}\right)$. By inserting $\mathrm{P}_{2}$ from Eq. (37) into Eq. (38) and after some algebraic manipulation, one obtains the following algorithm:

$$
\text { if } \Delta \mathrm{P}>0 \text { then } \mathrm{Q}=\mathrm{Q}_{0} \text { and } \mathrm{P}_{2}-\mathrm{P}_{3}=\left(\mathrm{Q}_{0} / \mathrm{A}_{\mathrm{v}}\right)^{2} \text { else } \mathrm{Q}=-\mathrm{Q}_{0} \text { and } \mathrm{P}_{2}-\mathrm{P}_{3}=-\left(\mathrm{Q}_{0} / \mathrm{A}_{\mathrm{v}}\right)^{2} \text {, }
$$

where

$$
\begin{gathered}
\mathrm{Q}_{0}=\frac{\mathrm{A}_{\mathrm{v}}}{2}\left[-\mathrm{CA}_{\mathrm{v}}+\sqrt{\left(\mathrm{CA}_{\mathrm{v}}\right)^{2}+4|\Delta \mathrm{P}|}\right], \\
\Delta \mathrm{P}=\mathrm{P}_{1}-\mathrm{P}_{3}, \\
\mathrm{~A}_{\mathrm{v}}=\mathrm{C}_{\mathrm{d}} \pi \mathrm{dx} \sqrt{\frac{2}{\rho},}
\end{gathered}
$$

and

$$
\mathrm{C}=\frac{128 \mu \mathrm{L}}{\pi \mathrm{d}^{4}}
$$

The force on the each flappler element can be modeled and the free body diagram is shown in Fig. 11.

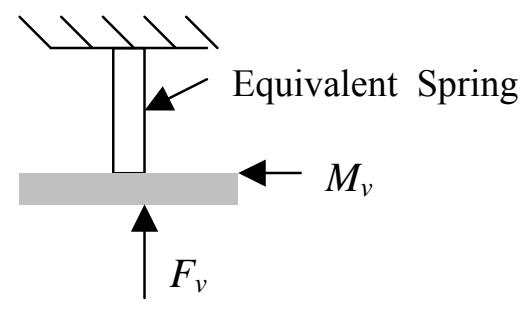

Fig. 11. Dynamic model of flapper valve. 
By balancing the forces, one obtains for the flapper valve the dynamic model as follows where $\Delta \mathrm{P}$ is now equal to $\mathrm{P}_{2}-\mathrm{P}_{3}$ :

$$
\begin{aligned}
& \mathrm{M}_{\mathrm{v}} \ddot{\mathrm{x}}_{\mathrm{v}}=\mathrm{F}_{\mathrm{v}}-\mathrm{K}_{\mathrm{s}}\left(\mathrm{x}_{\mathrm{v}}+\mathrm{x}_{\mathrm{v} 0}\right)-\mathrm{B}_{\mathrm{v}} \dot{\mathrm{x}}_{\mathrm{v}}, \\
& \mathrm{M}_{\mathrm{v}} \ddot{\mathrm{x}}_{\mathrm{v}}+\mathrm{B}_{\mathrm{v}} \dot{\mathrm{x}}_{\mathrm{v}}+\mathrm{K}_{\mathrm{s}} \mathrm{x}_{\mathrm{v}}=\left(1-\mathrm{E}_{1} \frac{\mathrm{A}_{12}}{\mathrm{~A}_{\mathrm{s}}}\right) \mathrm{A}_{\mathrm{s}} \Delta \mathrm{P}-\mathrm{K}_{\mathrm{s}} \mathrm{x}_{\mathrm{v} 0} \\
& \ddot{x}_{v}+\frac{B_{v}}{M_{v}} \dot{x}_{v}+\frac{K_{s}}{M_{v}} x_{v}=\frac{\left(1-E_{1} \frac{A_{12}}{A_{s}}\right) A_{s} \Delta P-K_{s} x_{v 0}}{M_{v}} \\
& \ddot{\bar{x}}_{v}+2 \omega_{v} \xi_{v} \dot{\bar{x}}_{v}+\omega_{v}^{2} \bar{x}_{v}=\omega_{v}^{2}\left[\frac{\left(1-E_{1} \frac{A_{12}}{A_{s}}\right) A_{s} \Delta P}{K_{s} x_{\max }}-\bar{x}_{v 0}\right],
\end{aligned}
$$

where

$$
\overline{\mathrm{x}}_{\mathrm{v}}=\frac{\mathrm{x}_{\mathrm{v}}}{\mathrm{x}_{\max }} \text { and } \overline{\mathrm{x}}_{\mathrm{v} 0}=\frac{\mathrm{x}_{\mathrm{v} 0}}{\mathrm{x}_{\max }}
$$

Figure 12 shows the overall flapper arrangement without balls on the pump chamber outlet.

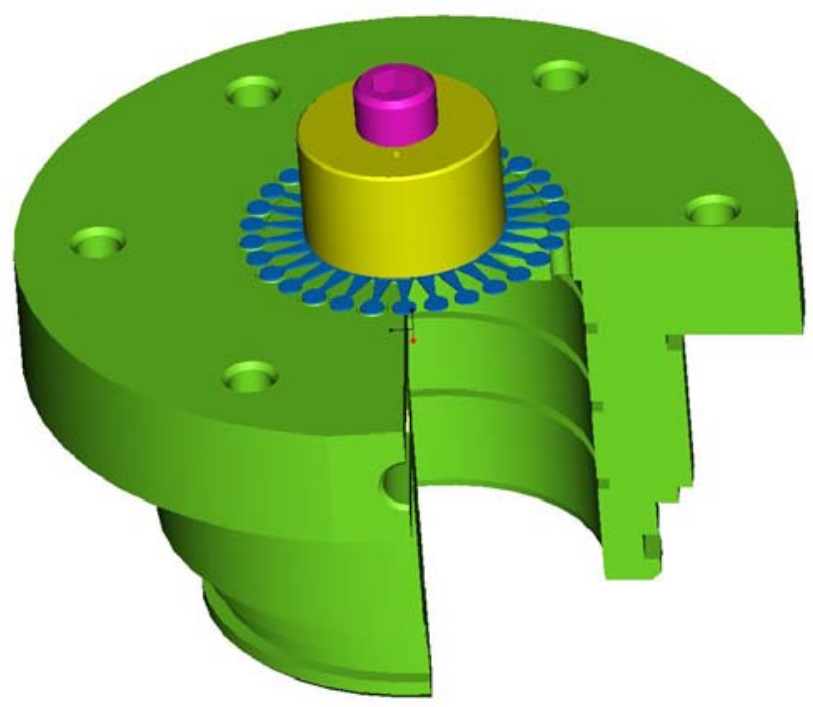

Fig 12. Piezoelectric pump valves.

There are 15 holes for the high pressure flappers and 30 holes for the low pressure flappers. 


\section{DESIGN ISSUES}

\subsection{APPROACH}

Our approach is to first perform a rough sizing calculation of the piezoelectric stack, flapper, chamber, and structure. Then we will construct the pump and measure the various parameters of the pump such as the valve frequency response. Finally, we will simulate on the computer based on the more detailed computer models as developed in Section 4 and make comparisons to the actual measured pump power and flow for various load conditions.

\subsection{SIZING RELATIONSHIPS}

The classical low-frequency electromechanical piezoelectric model is shown in Fig. 13 (note that a dc voltage bias from the voltage source is not shown but has a magnitude equal to the peak ac signal V). For maximum power transfer from the voltage source to the mechanical load $Z_{\mathrm{m}}$ assuming the

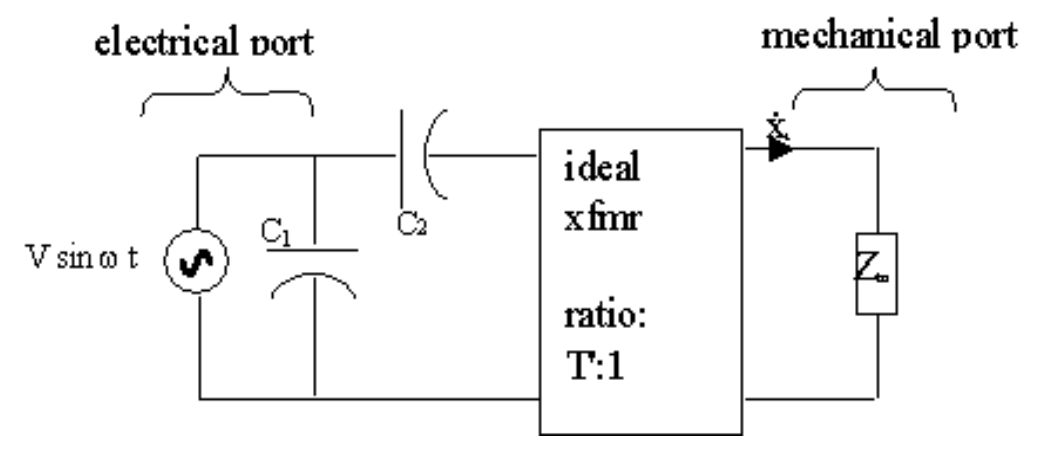

Fig. 13. Electromechanical model of piezoelectric stack and mechanical load.

mechanical load can be modeled as a pure resistor (i.e., inertial loading is ignored), $Z_{\mathrm{m}}$ must have the same magnitude of impedance as $\mathrm{C}_{2}$ element after being reflected through the transformer

$$
\mathrm{Z}_{\mathrm{m}}=\mathrm{R}_{\mathrm{m}}=\frac{1}{\mathrm{~T}^{\prime 2} \omega \mathrm{C}_{2}}
$$

The magnitude of the voltage drop across the load at the source side of the transformer will be $\mathrm{V} / \sqrt{2}$ which means that the maximum average power transfer is

$$
\mathrm{P}_{\mathrm{out}}^{\max }=\frac{\mathrm{V}^{2} \omega \mathrm{C}_{2}}{4}
$$

Since only half the power is actually transmitted during each pumping cycle due to the closure of the valves, the actual maximum power transfer would be 


$$
\mathrm{P}_{\text {out }}^{\max }=\frac{\mathrm{V}^{2} \omega \mathrm{C}_{2}}{8}
$$

The constituent equations for $\mathrm{C}_{2}$ is

$$
\mathrm{C}_{2}=\mathrm{k}^{2} \frac{\varepsilon_{33}^{\mathrm{T}} \text { Volume }}{\mathrm{t}^{2}}
$$

where

$$
\begin{array}{ll}
\varepsilon_{33}^{\mathrm{T}} & =\text { electric permittivity, } \\
\mathrm{t} & =\text { thickness of a single stack element, } \\
\text { Volume } & =\text { volume of piezoelectric stack, and } \\
\mathrm{k}^{2} & =\text { electrical to mechanical conversion constant. }
\end{array}
$$

Next, substitute Eq. (51) into Eq. (50) utilizing the definition of an electric field $E=V / t$ and $\omega=2 \pi f$, Eq. (50) becomes

$$
\mathrm{P}_{\text {out }}^{\max }=\frac{\pi}{8}\left(0.5 \varepsilon_{33}^{\mathrm{T}} \mathrm{E}_{\max }^{2}\right) \mathrm{f} \mathrm{k}^{2} \text { Volume }
$$

where $\mathrm{E}_{\max }$ is the maximum practical electric field (normally around $10^{6} \mathrm{~V} / \mathrm{m}$ which includes the dc offset, i.e., $\mathrm{V}=\mathrm{V}_{\max } / 2$ and $\mathrm{E}_{\text {max }}=\mathrm{V}_{\max } / \mathrm{t}$ ). The magnitude of the pressure on the load side of the transformer (i.e., the primary voltage reflected to the secondary) is

$$
\mathrm{P}_{\mathrm{m}}=\frac{2 \mathrm{~V}}{\mathrm{~T}^{\prime} \mathrm{A} \sqrt{2}}
$$

Substituting the constituent transformer $T^{\prime}=s_{33}^{E} t / d_{33} A$ into Eq. (53),

$$
P_{m}=2\left(\frac{V}{t}\right) \frac{d_{33}}{\sqrt{2} s_{33}^{E}}=\frac{E_{\text {max }} d_{33}}{\sqrt{2} s_{33}^{E}}
$$

Finally, the magnitude of the peak displacement velocity $\dot{\mathrm{x}}_{\mathrm{T}}^{\max }$ at maximum power transfer is

$$
\dot{\mathrm{x}}_{\mathrm{T}}^{\max }=\frac{\omega \mathrm{C}_{2} \mathrm{~V}}{\sqrt{2}} \mathrm{~T}^{\prime}=\frac{\pi \mathrm{f} \mathrm{L} \mathrm{d_{33 } \mathrm { E } _ { \operatorname { m a x } }}}{\sqrt{2}},
$$

where the defining relationships for $\mathrm{T}^{\prime}, \mathrm{C}_{2}$, and $\omega$ have been substituted into Eq. (55) where $L$ is the length of the piezoelectric stack. The maximum flow, $\mathrm{Q}^{\max }$, is equal to the peak displacement velocity time the chamber area, $A$, i.e.,

$$
\mathrm{Q}^{\max }=\frac{\pi \mathrm{fLd}_{33} \mathrm{AE}_{\max }}{\sqrt{2}}
$$


and the average flow, $\mathrm{Q}^{\text {avg }}$, assuming a half-sinusoidal waveform, is

$$
\mathrm{Q}^{\text {avg }}=\frac{\mathrm{fLd}_{33} \mathrm{~A} \mathrm{E}_{\max }}{\sqrt{2}}
$$

The following table summarizes the above results:

\begin{tabular}{|c|c|}
\hline Description & Governing relationship \\
\hline Maximum Power Transfer & $\mathrm{P}_{\text {out }}^{\max }=\frac{\pi}{16}\left(\varepsilon_{33}^{\mathrm{T}} \mathrm{E}_{\max }^{2}\right) \mathrm{fk}^{2}$ Volume \\
\hline Pressure at Maximum Power Transfer & $\mathrm{P}_{\mathrm{m}}=\frac{\mathrm{E}_{\max } \mathrm{d}_{33}}{\sqrt{2} \mathrm{~s}_{33}^{\mathrm{E}}}$ \\
\hline Peak Flow at Maximum Power Transfer & $\mathrm{Q}^{\max }=\frac{\pi \mathrm{f} \mathrm{\textrm {d } _ { 3 3 }} \mathrm{A} \mathrm{E}_{\text {max }}}{\sqrt{2}}$ \\
\hline Average Flow at Maximum Power Transfer & $\mathrm{Q}^{\mathrm{avg}}=\frac{\mathrm{fL} \mathrm{d}_{33} \mathrm{~A} \mathrm{E} \mathrm{E}_{\max }}{\sqrt{2}}$ \\
\hline
\end{tabular}

Two additional relationships are needed. Stack length for maximum displacement under no load is simply

$$
\mathrm{L}=\frac{\mathrm{x}_{\mathrm{T}}^{\max }}{\mathrm{d}_{33} \mathrm{E}^{\max }}
$$

which is obtained from Eq. (6). The effective no load capacitance is $\mathrm{C}_{0}$ which can be rewritten from Eq. (12) to be

$$
\mathrm{C}_{0}=\frac{\mathrm{NA}}{\mathrm{t}} \varepsilon_{33}^{\mathrm{T}}=\frac{\text { Volume }\left[0.5 \varepsilon_{33}^{\mathrm{T}}\left(\mathrm{E}^{\max }\right)^{2}\right]}{0.5\left(\mathrm{~V}^{\max }\right)^{2}}
$$

\subsection{PIEZOELECTRIC STACK SIZING}

With the lack of availability of a single crystal stack for this project, a conventional piezoelectric material was utilized. The piezoelectric material used was from Kinetic Ceramics, Inc. and the material was from their PZWT-100 series. The key properties for this material are:

$$
\mathrm{d}_{33}=370 \times 10^{-12} \mathrm{~m} / \mathrm{V}
$$




$$
\begin{gathered}
\text { density }=7800 \mathrm{~kg} / \mathrm{m}^{3} \\
\mathrm{~s}_{33}^{\mathrm{E}}=1 / \mathrm{Y}_{33}^{\mathrm{E}}=1 / 4.8 \times 10^{+10} \mathrm{~m}^{2} / \mathrm{N} \\
\varepsilon_{33}^{\mathrm{T}}=2500 \times \varepsilon_{0} \text { farads } / \mathrm{m} \\
\varepsilon_{0}=8.854 \times 10^{-12} \text { farads } / \mathrm{m} \\
\mathrm{k}=0.64 \\
\mathrm{E}_{\max }=1.25 \times 10^{6} \mathrm{~V} / \mathrm{m} \\
\text { dissipation factor }=2.7 \%
\end{gathered}
$$

It is desirable to set $\mathrm{x}_{\mathrm{t}}^{\max }$ as large as possible. After talking with the vendor, the smallest value that the design team thought was feasible was $x_{t}^{\max }=85 \mu \mathrm{m}$. Based on Eq. (58), the stack length is about 4.75 in. Assuming a power out of $200 \mathrm{~W}$ and an operating frequency at $500 \mathrm{~Hz}(500 \mathrm{~Hz}$ is a somewhat arbitrary number that we will try to verify during experimentation, the volume of the piezoelectric stack can be derived from Eq. (52) as

$$
\text { Volume }=\frac{\mathrm{P}_{\mathrm{out}}^{\max }}{\frac{\pi}{16}\left(\varepsilon_{33}^{\mathrm{T}} \mathrm{E}_{\max }^{2}\right) \mathrm{f} \mathrm{k}^{2}}
$$

The volume comes out to $3.4 \mathrm{in}^{3}$ which makes the area approximately $0.76 \mathrm{in}^{2}$. The no-load calculated capacitance $\mathrm{C}_{0}$, based on Eq. (59) is roughly $4.9 \mathrm{uF}$. The closest stack that would roughly meet these sizing valves is Kinetic Ceramics' stack D125120 which has a maximum displacement of $120 \mu \mathrm{m}$ and an equivalent area of $1.156 \mathrm{in}^{2}$.

Losses in the piezoelectric stack can be calculated from the dissipation value,

$$
\mathrm{P}_{\text {loss }}=\left(\frac{\mathrm{V}_{\text {peak-peak }}}{2}\right)^{2} 2 \pi \mathrm{fC} \text { (Dissipation) }
$$

Substituting the material and operation valves, one obtains

$$
\mathrm{P}_{\text {loss }}=\left(\frac{1000}{2}\right)^{2} 2 \pi 5004.9 \times 10^{-6}(0.027) \cong 100 \mathrm{~W}
$$

This loss represents approximately $50 \%$ of the total power out of the actuator. While this is a very large number, the final actuator would be composed of a different piezoelectric material (single crystal, PZN-PT) that has a dissipation value of $<1 \%$ (Park, 1997). 


\subsection{FLAPPER AND BALL VALVE SIZING}

From Eq. (56), peak flow is around $66 \mathrm{cc} / \mathrm{sec}$. Using the relationships described by Eqs. (39)-(42) where the maximum stress allowed is equal to the tensile strength of 1650 steel (147 kpsi) divided by a safety factor (a value of 2.3 will give infinite life), the peak flow of all of the flappers versus the pressure drop across the flapper is shown in the graph below for a safety factor of 2.3. Basically, the maximum stress seen by the flapper can be approximated as

$$
\sigma^{\max }=\frac{\mathrm{K}_{\mathrm{s}} \mathrm{x}_{\text {flapper }}^{\max } \mathrm{L}_{\text {flapper }}}{\mathrm{b}_{0} \mathrm{t}^{2} / 6}
$$

Next, solve for $x_{\text {flapper }}^{\max }$ in terms of maximum stress and then insert this result into Eqs. (39)-(42). From Fig. 14, it is clear that fairly low pressure drop will be seen by each of the flapper valves.

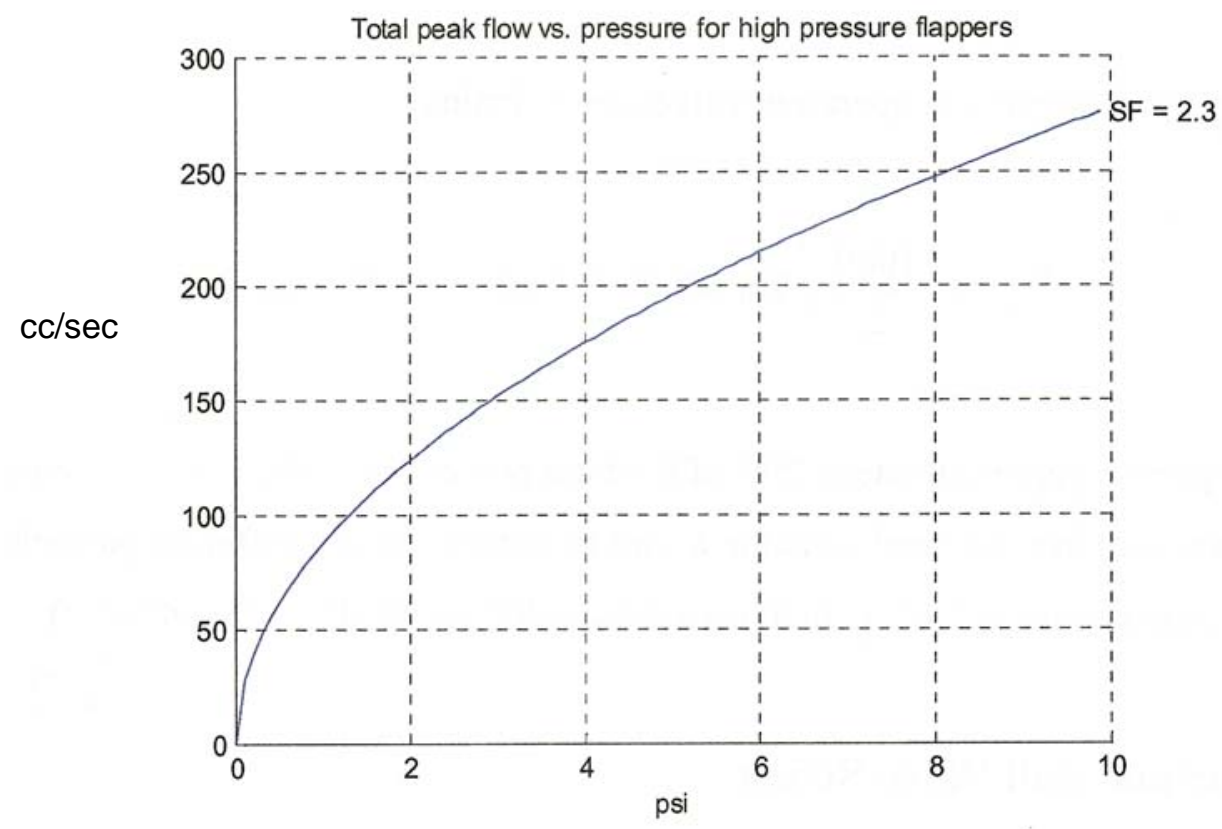

Fig. 14. Flow vs. pressure for 0.003 in thickness for flapper.

\subsection{CHAMBER AND PISTON SIZING}

\subsubsection{General Design Considerations}

Based on the basic definition of fluid compliance, the bulk modulus, $\beta$, is related to volume change, $\Delta \mathrm{V}^{\max }$, and pressure change, $\Delta \mathrm{P}^{\max }$, by

$$
\beta=-\frac{\mathrm{V}_{0}}{\Delta \mathrm{V}^{\max }} \Delta \mathrm{P}^{\max }
$$

where 


$$
\begin{aligned}
& \mathrm{V}_{0}=\mathrm{AL}_{\text {chamber }}+\mathrm{V}_{\text {tubes }}, \\
& \Delta \mathrm{V}^{\text {max }}=-\mathrm{A} \Delta \mathrm{x}^{\text {max }}, \\
& \Delta \mathrm{P}^{\max }=\frac{\mathrm{A} \Delta \mathrm{x}^{\max } \beta}{\mathrm{A} \mathrm{L}_{\text {chamber }}+\mathrm{V}_{\text {tubes }}}, \\
& \beta=\text { fluid bulk modulus (ranges from } 100,000 \text { to } 200,000 \mathrm{psi} \text { ), } \\
& \Delta \mathrm{x}^{\text {max }}=90 \mathrm{um}, \\
& \mathrm{L}_{\text {chamber }}=450 \text { um }, \\
& A=\text { area of chamber }=6.45 \mathrm{~cm}^{2}\left(\text { or } 1 \mathrm{in}^{2}\right) \text { and } \\
& \mathrm{V}_{\text {tubes }}=15\left(0.202 \pi \frac{0.071^{2}}{4}\right)=0.0122 \mathrm{in}^{3}=0.2 \mathrm{~cm}^{3} .
\end{aligned}
$$

There are 15 outlet ports in an effort to minimize the volume in the tubes. For the inlet ports, there are 30 tubes which are not critical from a total fluid volume minimization since we are trying to get the fluid into the chamber from the reservoir. For $\beta=100,000 \mathrm{psi}, \Delta \mathrm{P}^{\max }=11,854 \mathrm{psi}$ and for $\beta=200,000 \mathrm{psi}$, $\Delta \mathrm{P}^{\max }=23,708 \mathrm{psi}$. For the lower bulk modulus number to achieve $1,000 \mathrm{psi}$ of pressure in the chamber, it would require $1,000 / 11,854=0.084$ or $8.4 \%$ of the stroke of the piezoelectric stack before the valves would open. If the bulk modulus is 200,000 psi, then $4.2 \%$ of the stroke of the piezoelectric stack is wasted in compressing the fluid. In conclusion, while it is difficult to estimate the fluid bulk modulus numerical valve in an actual apparatus for mineral oil, the lossess associated with the compression of the fluid will be between these two numbers ( 4.2 to $8.4 \%)$.

Mass of piston (see Fig. 20 for a view of the piston) will be limited to $1 / 3$ the mass of the piezoelectric stack (i.e., around $.1 \mathrm{~kg}$ ). The total acceleration force will be:

Facc $=($ mass of piston + effective mass of piezoelectric stack $) *(\text { max angular velocity })^{2} *($ maximum displacement $/ 2)=(.21) *\left(2 * \mathrm{pi}^{*} 1,000\right)^{2} *\left(90 * 10^{-6} / 2\right)=373 \mathrm{~N}$

This force is well below the required preload force that will be applied to the stack during installation to prevent damage to the stack.

\subsubsection{Optimization of Chamber Area}

The previous section attempted to address the initial dimensions of the chamber. This section will utilize the computer simulation models utilizing the physics based models discussed in Section 4. The voltage to the stack will be a sinusoid voltage of $500 \mathrm{~V}$ with a positive de voltage of $500 \mathrm{~V}$ for a total of $1,000 \mathrm{~V}$ to be applied to the stack. Since the model for the stack is based on current being injected into the stack, a voltage control loop is required and is shown in Fig. 15 (software has been written in the Simulink environment which is a MathWork's product). The controller is a proportional controller since the piezoelectric model looks approximately like a first-order lag to the current source. 


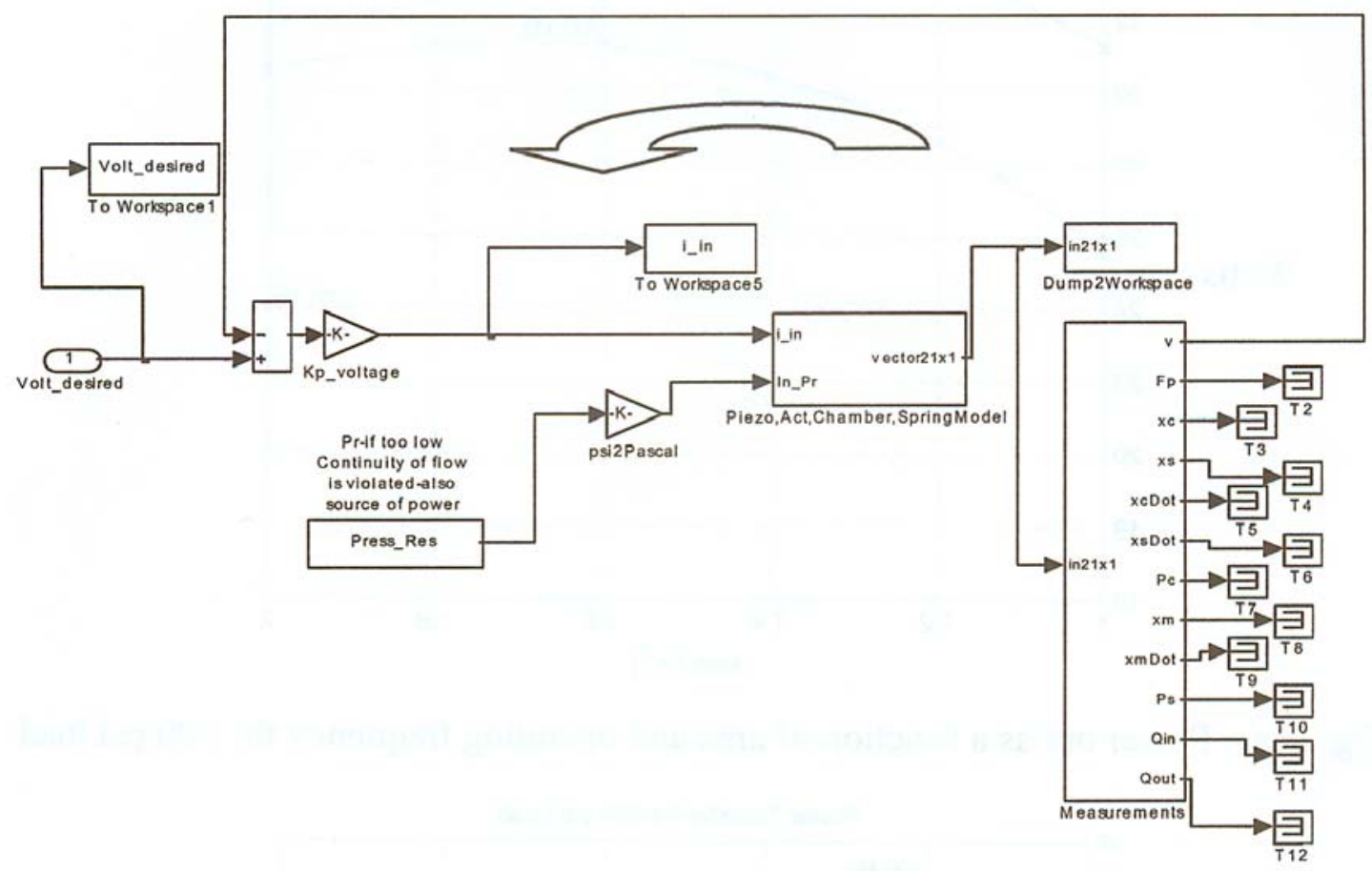

Fig. 15. Voltage to current control loop.

By changing the chamber area, pumping frequency and the load drop, a set of curves (see Figs. 16a, 16b, and 16c) can be generated that shows roughly the optimal area for the chamber. At $200 \mathrm{~Hz}$ the area should be 2 in $^{2}$ for a 300 psi load and $1.4 \mathrm{in}^{2}$ at $400 \mathrm{~Hz}$. For a $600 \mathrm{psi}$ load, this same relationship holds but the area at $400 \mathrm{~Hz}$ should be around $1.2 \mathrm{in}^{2}$. If we could continue running the stack at a higher frequency, the stack area, according to the simulation, should be made smaller. We decided to keep the present area size of $1 \mathrm{in}^{2}$ since our current power supply can produce sufficient current slightly greater than $400 \mathrm{~Hz}$ with $1,000 \mathrm{~V}$ peak to peak. 


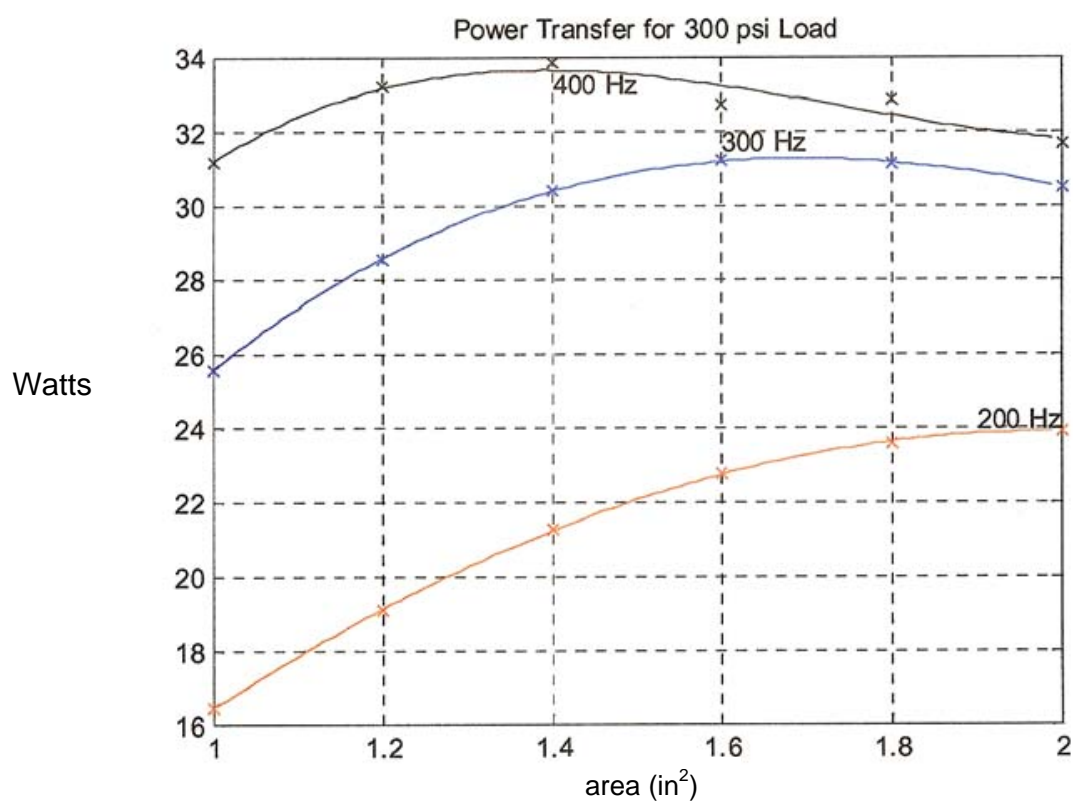

Fig. 16a. Power out as a function of area and operating frequency for $300 \mathrm{psi}$ load.

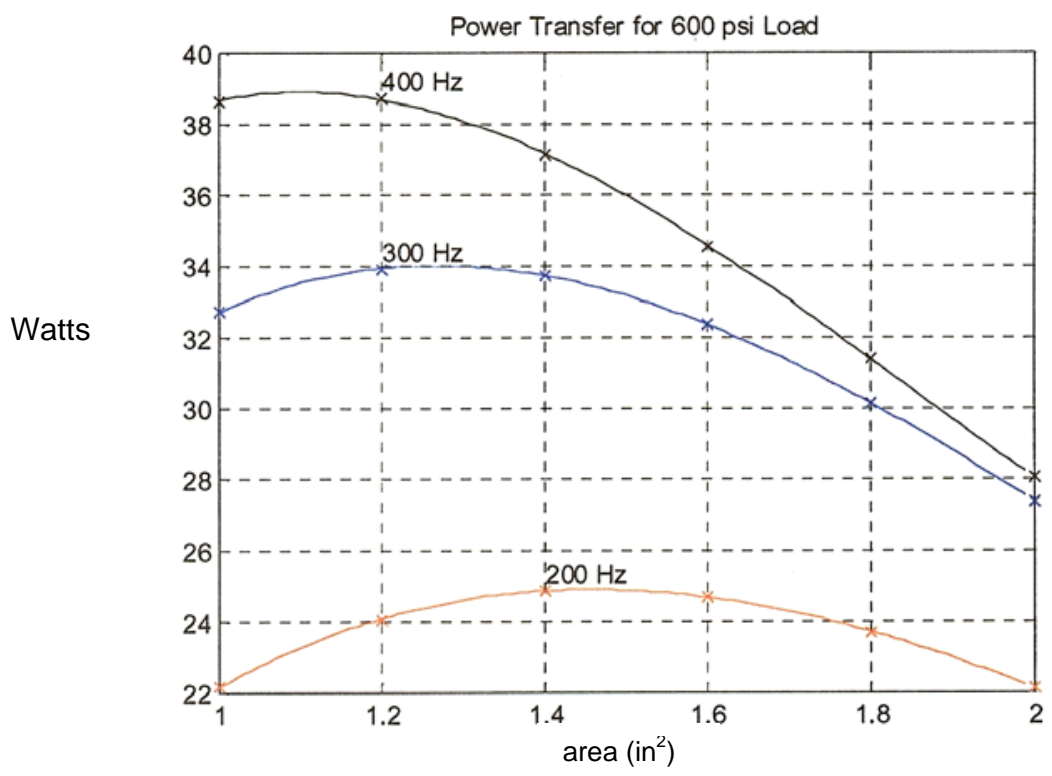

Fig. 16b. Power out as a function of area and operating frequency for $600 \mathrm{psi}$ load. 


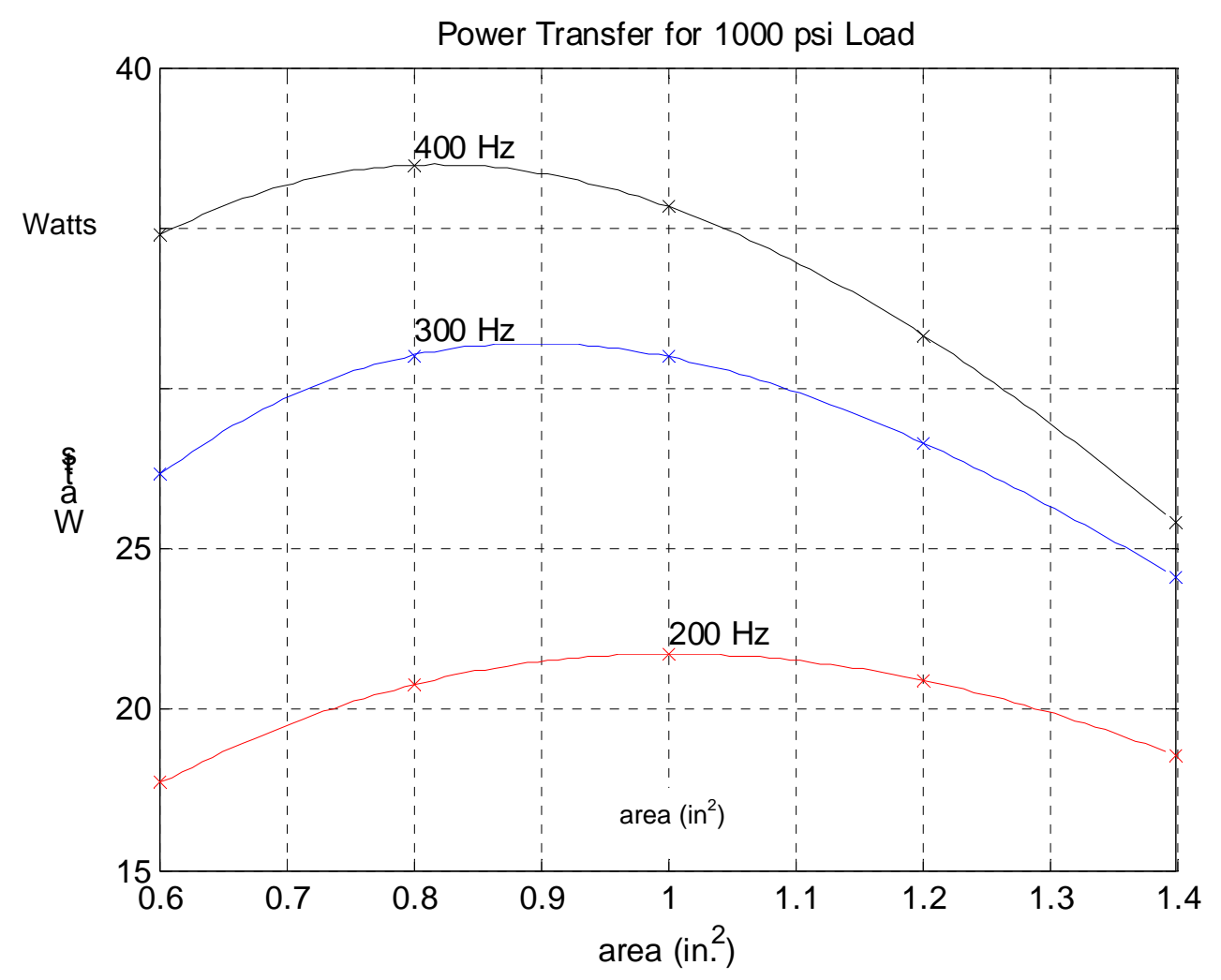

Fig. 16c. Power out as a function of area and operating frequency for 1,000 psi load.

\subsection{SUPPORT STRUCTURE SIZING}

The support structure stiffness will be designed to be around 10 times the piezoelectric stiffness. This will allow (for all practical purposes) all of the piezoelectric stack force to be applied to the pumping chamber. The piezoelectric stack stiffness is currently $200 \mathrm{~N} / \mu \mathrm{m}$ requiring the support structure stiffness to be around $2,000 \mathrm{~N} / \mu \mathrm{m}$ or $14.1 \times 10^{6} \mathrm{lb} / \mathrm{in}$. Assuming cylindrical outer shell for the support housing, the stiffness of the housing would be $\mathrm{E} \mathrm{A} / \mathrm{L}$ where $\mathrm{E}$ is the Youngs Modulus, A is the cross-sectional area, and $\mathrm{L}$ is the length. Letting $\mathrm{L}=3.53$ in (length of piezoelectric stack) and $\mathrm{E}=28 \times 10^{6} \mathrm{psi}$, then A should be at least $1.78 \mathrm{in}^{2}$. For the support structure, the inner diameter is 1.25 in and the outer diameter is 2.0 in giving an effective area of $1.91 \mathrm{in}^{2}$.

\subsection{OVERVIEW DRAWINGS OF FINAL DESIGN}

Figures $17 \mathrm{a}$ and $17 \mathrm{~b}$ show the overview drawing of the piezoelectric pump. 


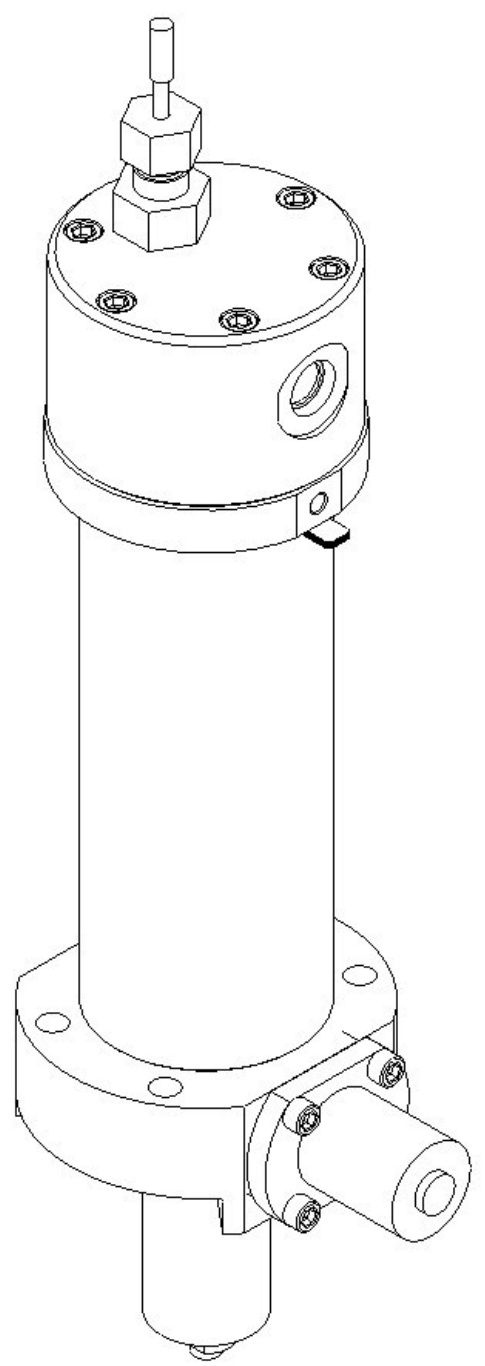

Fig. 17a. Overview drawing of the pump.

The bottom piece contains an lvdt sensor used only for testing. Likewise, the top piece protruding out of the actuator is an optical sensor used to measure motion of the flappers again used only for testing. 

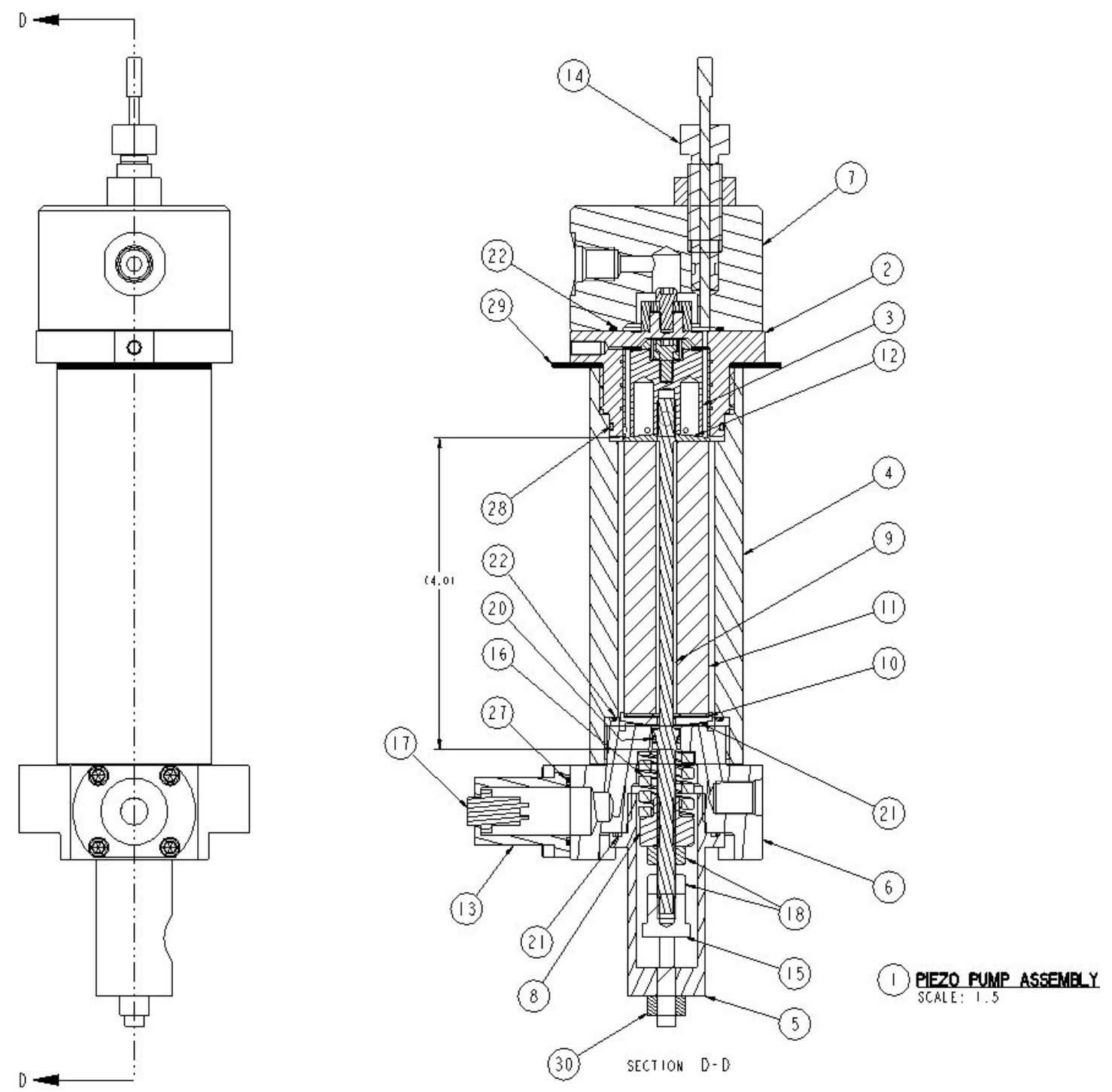

Fig. 17b. Detail assembly drawing.

Electrical connectors ( bottom left of pump - Parts 13 and 17) are oversized to allow easy connection to the pump. The lvdt and the optical sensors (bottom and top of pump - Parts 14 and 15) are easily seen. 


\begin{tabular}{|c|c|c|c|c|c|c|c|}
\hline & 1 & & PIE $20-8 k 01-022-1$ & JAM NUT & & & 30 \\
\hline & $A R$ & & PIEZ0-8K0I-020-I & HOUSING SHIMS & & & 29 \\
\hline & 1 & & -028 & O-RING & & & 28 \\
\hline & 1 & & -018 & $0-R \mid N G$ & & & 27 \\
\hline & 1 & & $\begin{array}{l}\# 8-32 \text { UNC-2A } \\
X .375 \text { LONG }\end{array}$ & $\begin{array}{l}\text { SOCKET HEAD SET SCREW } \\
\text { FLAT NOSE }\end{array}$ & & & 26 \\
\hline & 1 & & $7 / 16^{2}-20$ UNF & HEX JAM NUT & & & 25 \\
\hline & 1 & & PHILTEC D64 & SENSOR & & & 24 \\
\hline & 4 & & $\begin{array}{l}\# 8-32 \text { UNC }-2 A \\
\times .50 \text { LONG } \\
\end{array}$ & SOCKET HEAD CAP SCREW & & & 23 \\
\hline & 2 & & -027 & O-RING & & & 22 \\
\hline & 1 & & PIE $20-8 K 01-02 I-I$ & TAB WASHER & & & 21 \\
\hline & 1 & & -010 & O-RING W/ PARBAK & & & 20 \\
\hline & 6 & & $\begin{array}{l}\# 10-24 U N C-2 A \\
\times 1.75 \text { LONG }\end{array}$ & SOCKET HEAD CAP SCREW & & & 19 \\
\hline & 2 & & $1 / 4 "-28 U N F$ & HEX JAM NUT & & & 18 \\
\hline & 1 & & FISCHER DBPEI02 & CONNECTOR & & & 17 \\
\hline & 1 & & CV0625-1000-093 & SPRING & ASSOC IATED & SPRING INC. & 16 \\
\hline & 1 & & PIEZ0-8K01-018-I & SENSOR TARGET & & & 15 \\
\hline & 1 & & PIEZ0-8K0I-016-I & SENSOR COLLAR & & & 14 \\
\hline & 1 & & $P|E Z 0-8 K 0|-0 \mid 4-1$ & CONNECTOR HOUSING & & & 13 \\
\hline & 1 & & $P \mid E 20-8 k 01-01 I-I$ & SPHERICAL_WASHER_MALE & & & 12 \\
\hline & 1 & & & PIEZO_STACK & & & 11 \\
\hline & $A R$ & & PIEZ0-8k0I-019-I & WASHER SHINS & & & 10 \\
\hline & 1 & & PIE $20-8 K 0 I-0 \mid ?-I$ & TENSIONER_SCREW & & & 9 \\
\hline & I & & PIEZ0-8K0I-010-I & SPRING_CAP & & & 8 \\
\hline & 1 & & PIEZ0-8K0I-0I3-I & TOP_END_CAP & & & 7 \\
\hline & 1 & & $P \mid E Z 0-8 K 01-012-1$ & BOTTOM_END_CAP & & & 6 \\
\hline & 1 & & PIE $20-8 k 01-015-I$ & BOTTOM_COVER & & & 5 \\
\hline & 1 & & PIEZ0-8K0I-009-I & HOUSING & & & 4 \\
\hline & 1 & & PIEZ0-8K0I-003-I & PISTON SUBASSEMBLY & & & 3 \\
\hline & 1 & & PIE $20-8 K 01-002-I$ & CYLINDER SUBASSEMBLY & & & 2 \\
\hline & 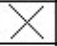 & & -1 & PIEZO PUMP ASSEMBLY & & & 1 \\
\hline 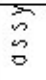 & \multirow[t]{2}{*}{7} & $\begin{array}{l}\text { CAGE } \\
\text { CODE } \\
\end{array}$ & $\begin{array}{c}\text { PART OR } \\
\text { IDENTIFYING NO }\end{array}$ & $\begin{array}{l}\text { NOMENCLATURE } \\
\text { OR DESCRIPTION }\end{array}$ & MATERIAL & SPECIFICATION & $\begin{array}{c}\text { FIND } \\
\text { NO }\end{array}$ \\
\hline 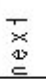 & & 4 & $\begin{array}{c}\text { NEXT } \\
\text { ASSEMBLY }\end{array}$ & \multicolumn{3}{|c|}{ PARTS LIST } & \\
\hline
\end{tabular}

Fig. 17b (cont.). Corresponding components from previous page. 


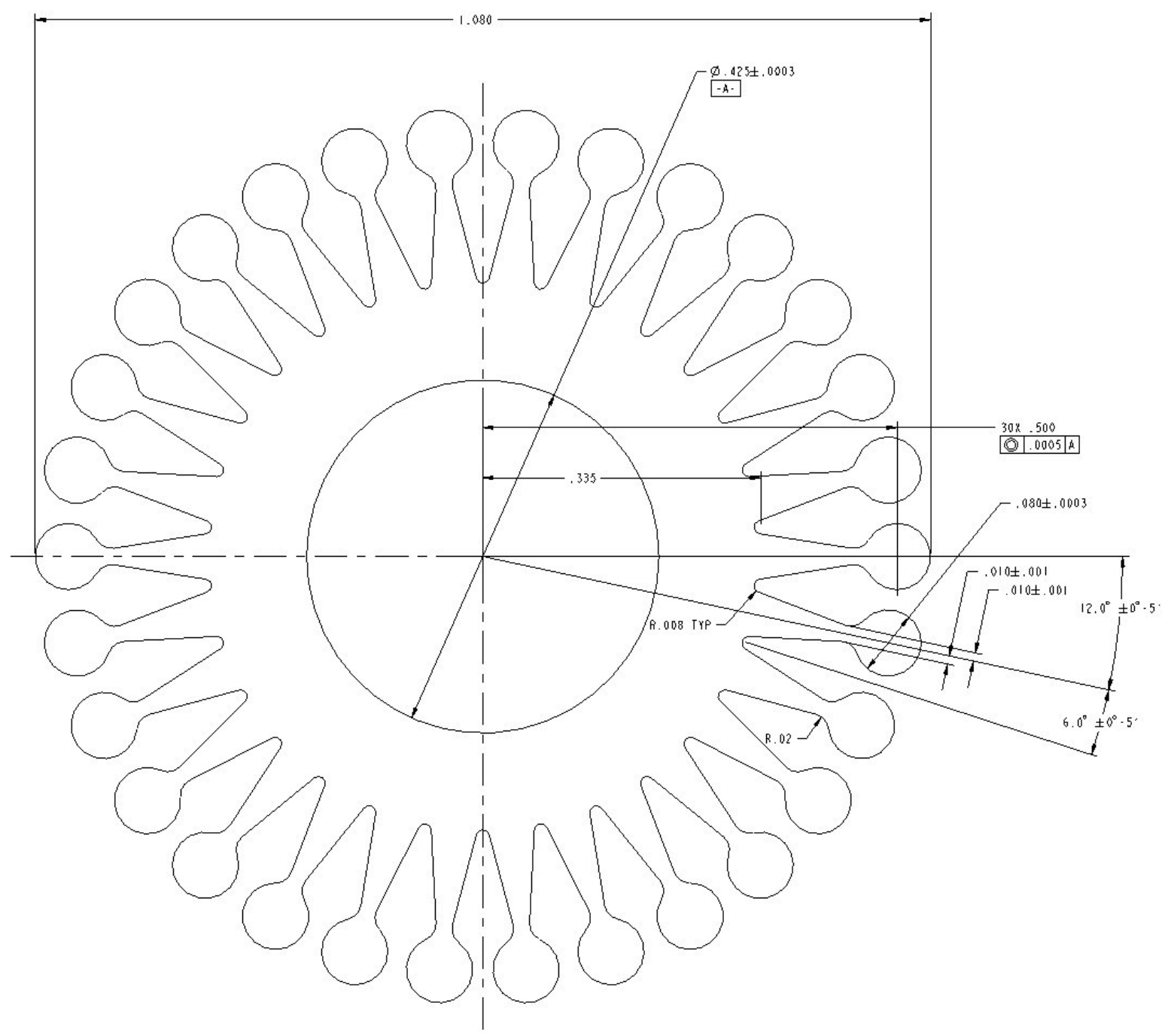

Fig. 18. Flapper valve design.

Three different flapper thickness will be tried: $0.003 \mathrm{in}, 0.007 \mathrm{in}$, and $0.0095 \mathrm{in}$. The same flapper design is used for the inlet and outlet ports; however, only half of the inlet flappers will be utilized. The balls that the flappers will hold in place (not shown in the above figure) are made out of ruby sapphire with a density of $0.144 \mathrm{lbs} / \mathrm{in}^{3}$ which is one-half the density of steel and are shown in Fig. 27. 


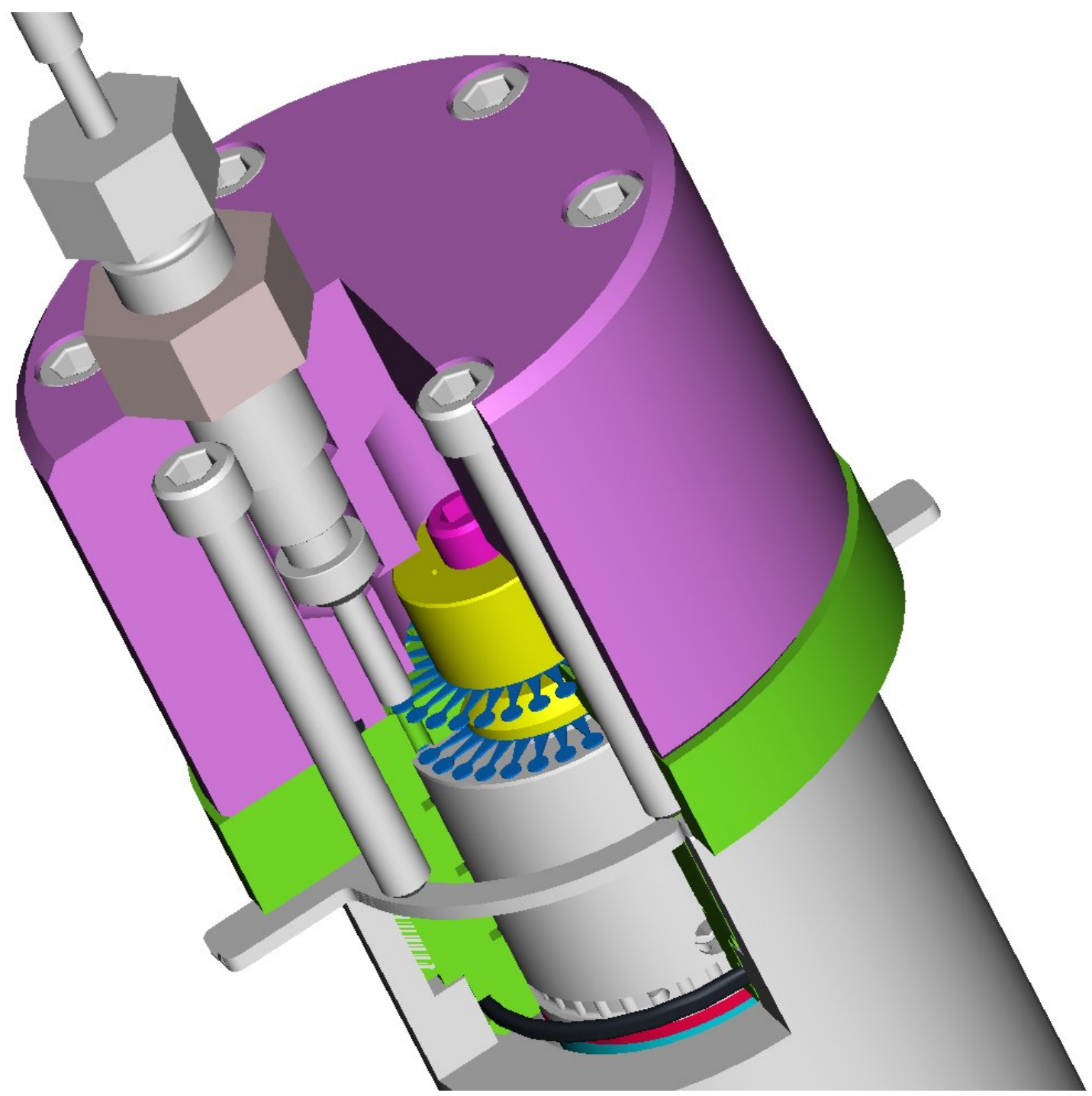

Fig. 19. Cutaway showing the two flapper pieces.

This drawing shows the two flapper locations in the pump. 


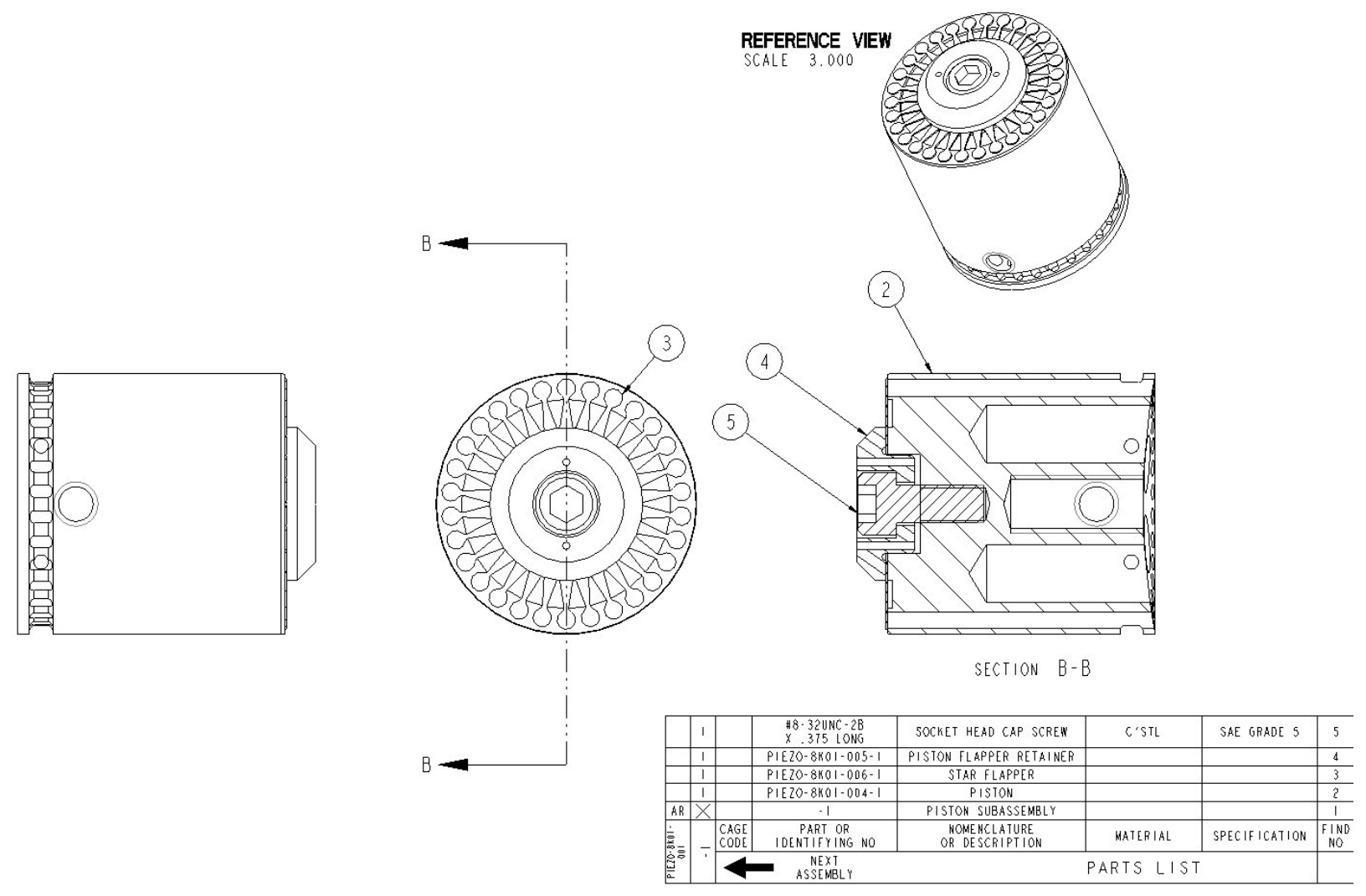

Fig. 20. Piston drawing.

Material being used for the piston is an aluminum bronze material. Holes have been drilled inside the material to allow air to escape. Overall weight must be below $100 \mathrm{~g}$ as previously discussed in Section 5.5.1. 


\section{PERFORMANCE MEASUREMENTS OF PUMP COMPONENTS AND PUMP}

\subsection{RESONANT FREQUENCY VERIFICATION}

To verify the natural frequencies of the flapper design, actual flapper valves were fabricated and were clamped. An optical sensor was utilized to measure the ringing in the valve when the valves were displaced from equilibrium. The experimental setup is shown in Figs. 21a and 21b.

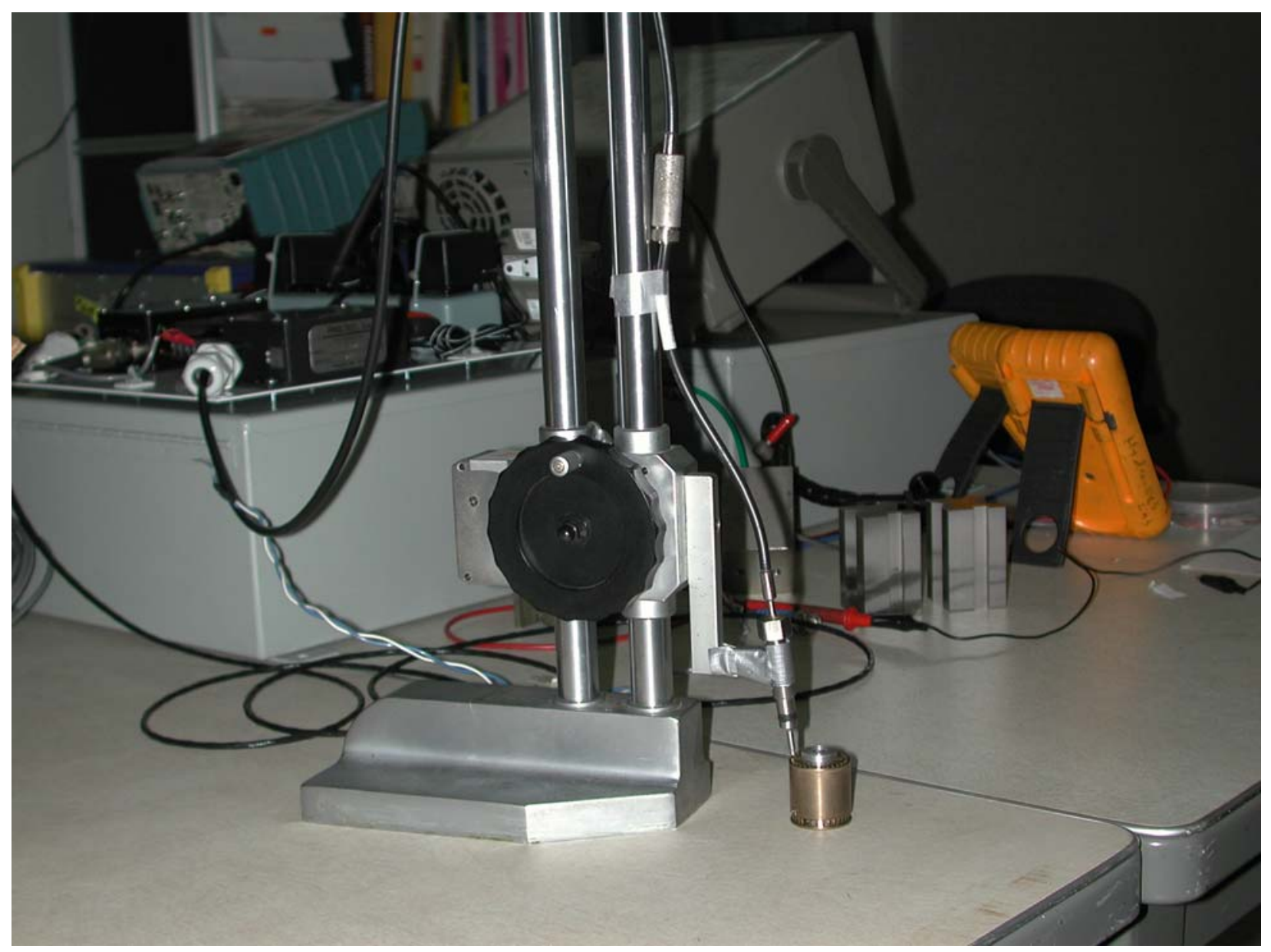

Fig. 21a. Experimental setup to determine flapper valve natural frequency (height gauge holding an optical sensor that can measure the vibration on the flapper element is shown). 


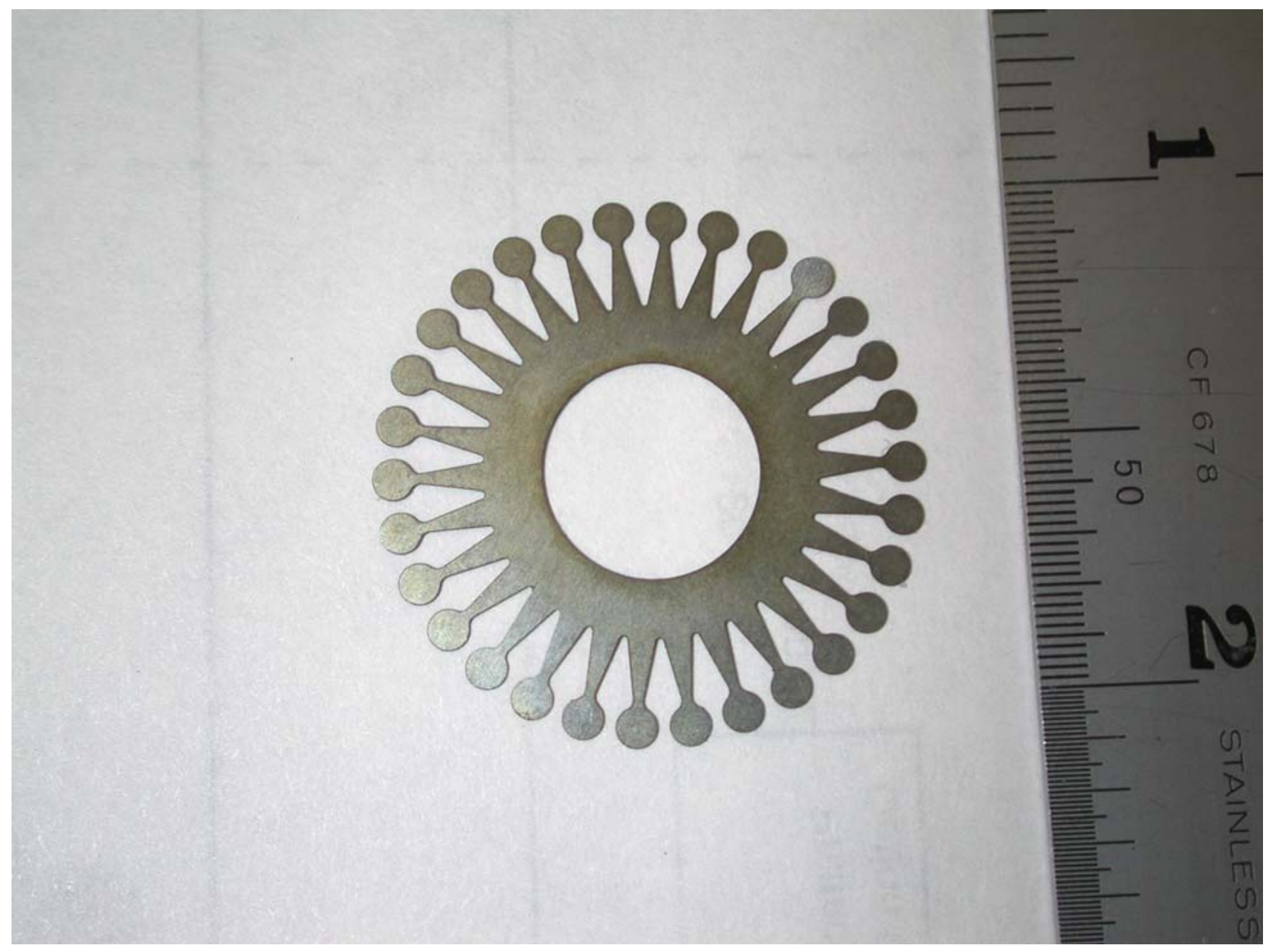

Fig. 21b. Test flapper.

The vibration tests of the flappers were captured by a data logging system and the results are shown in Figs. 22-24. 


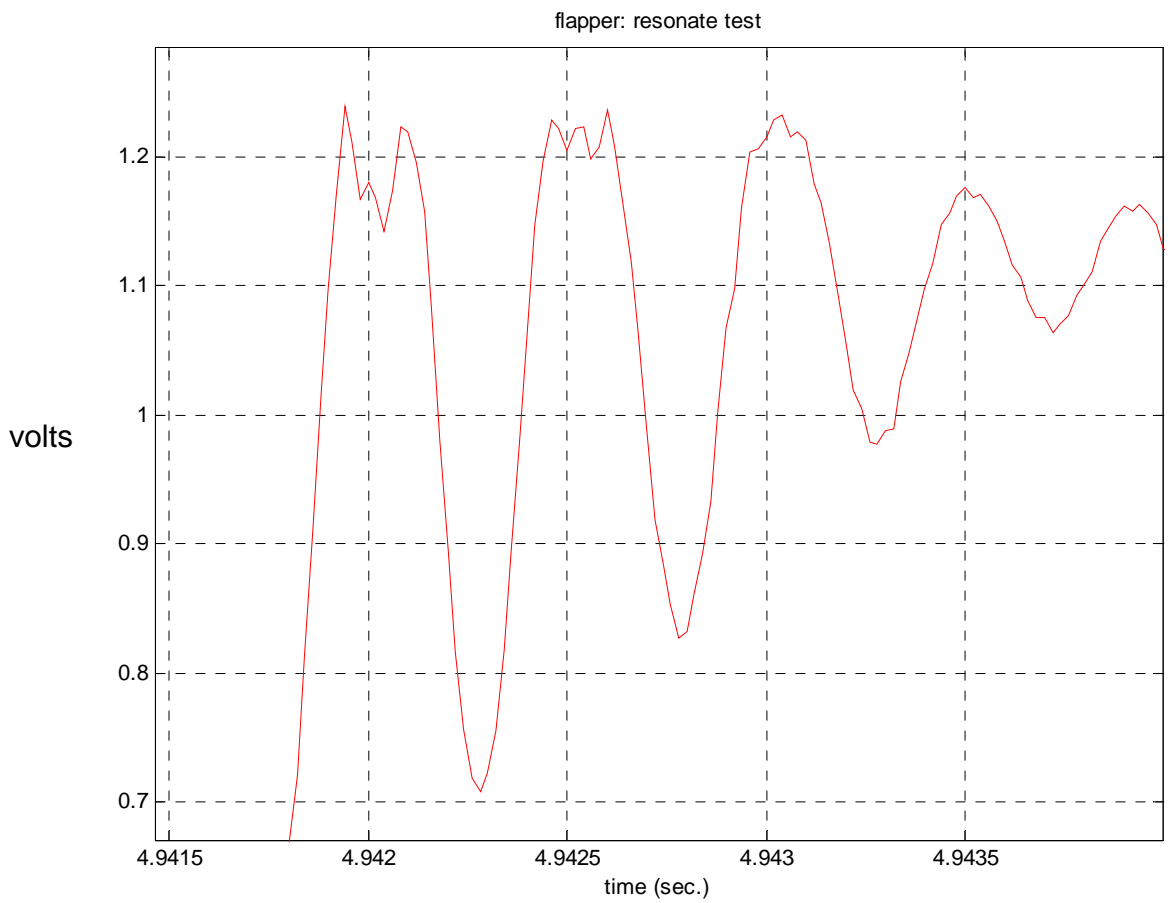

Fig. 22. Flapper with thickness $=0.003$ in, resonate fundamental frequency approximately $2 \mathrm{kHz}$.

This measurement corresponds very well with the calculated value of $2 \mathrm{kHz}$.

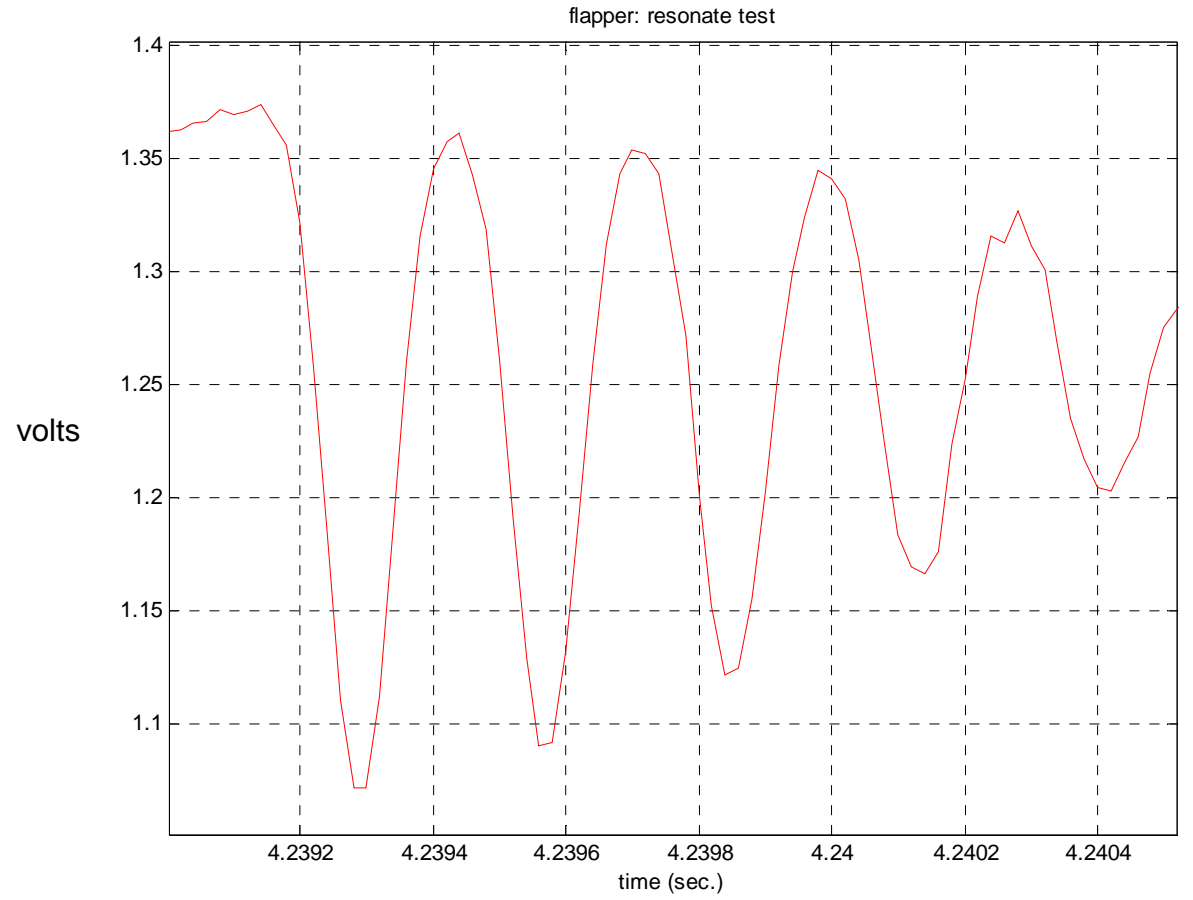

Fig. 23. Flapper with thickness $=0.007$ in, resonate frequency approximately $3.7 \mathrm{kHz}$. 
The calculated value of the resonate fundamental frequency was $4.6 \mathrm{kHz}$. A likely explaination of the discrepancy is that when the flapper was clamped we did not have a rigid connection (i.e., damping was introduced).

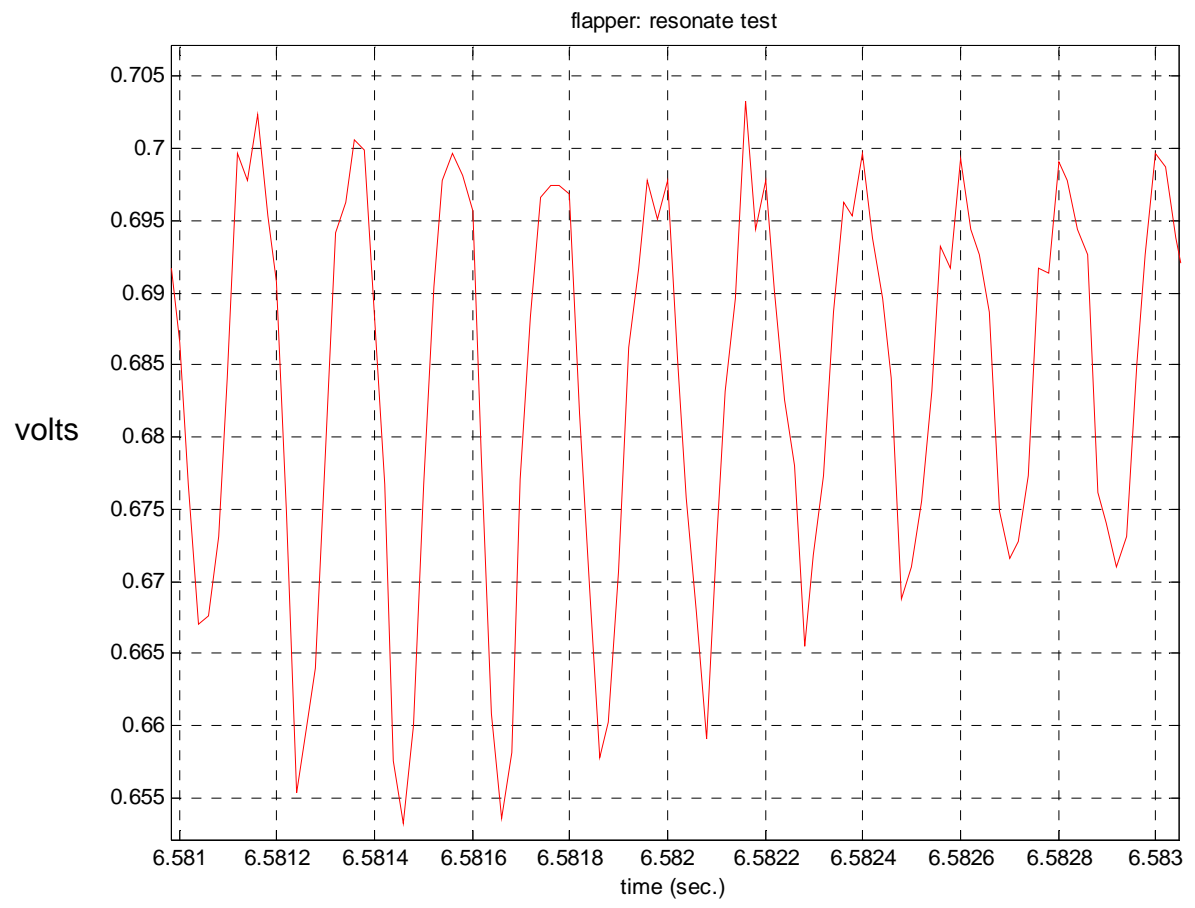

Fig. 24. Flapper with thickness $=0.0095$ in, resonate frequency approximately $5 \mathrm{kHz}$.

The calculated value of the resonate fundamental frequency was $6.2 \mathrm{kHz}$. Again, the discrepancy during the experiment might have occurred because the clamped end of the spring did not have a rigid connection (i.e., damping was introduced). Experimentally we have verified that the flapper valve can be designed to have a natural frequency at or above $2 \mathrm{kHz}$.

\subsection{STACK POLARIZATION IMPACT ON THE POWER ELECTRONICS}

Polarization, $\mathrm{P}$, of the piezoelectric material has been assumed to be linearly related to the electric field (i.e., $P=\varepsilon_{0} X_{e} E$ where $X_{e}$ is the electric susceptibility and has been assumed to be a constant). This assumption appears to be incorrect and appears to be related to the applied voltage to the piezoelectric stack. To demonstrate this relationship, a smaller piezoelectric stack (from PI, Inc., stack \#P-244.47) was selected and a no load test performed. The input capacitance of the stack was calculated based on measuring the applied voltage (sinusoid with dc offset), sinusoidal current, and phase shift between the sinusoidal voltage and current. The input capacitance is $\mathrm{C}_{1}$ and $\mathrm{C}_{2}$ in parallel (see Fig. 3) and in the linear case should be directly proportional to $\varepsilon_{\mathrm{r}}$ which should be equal to $1+\mathrm{X}_{\mathrm{e}}$. As can be seen from Fig. 25, the input capacitance varies significantly based on the applied voltage (roughly $8 \mathrm{nF} / 100 \mathrm{~V}$ ). To properly size the power electronics, the piezoelectric material needs to be tested at the rated voltage to determine worse case reactive currents. 


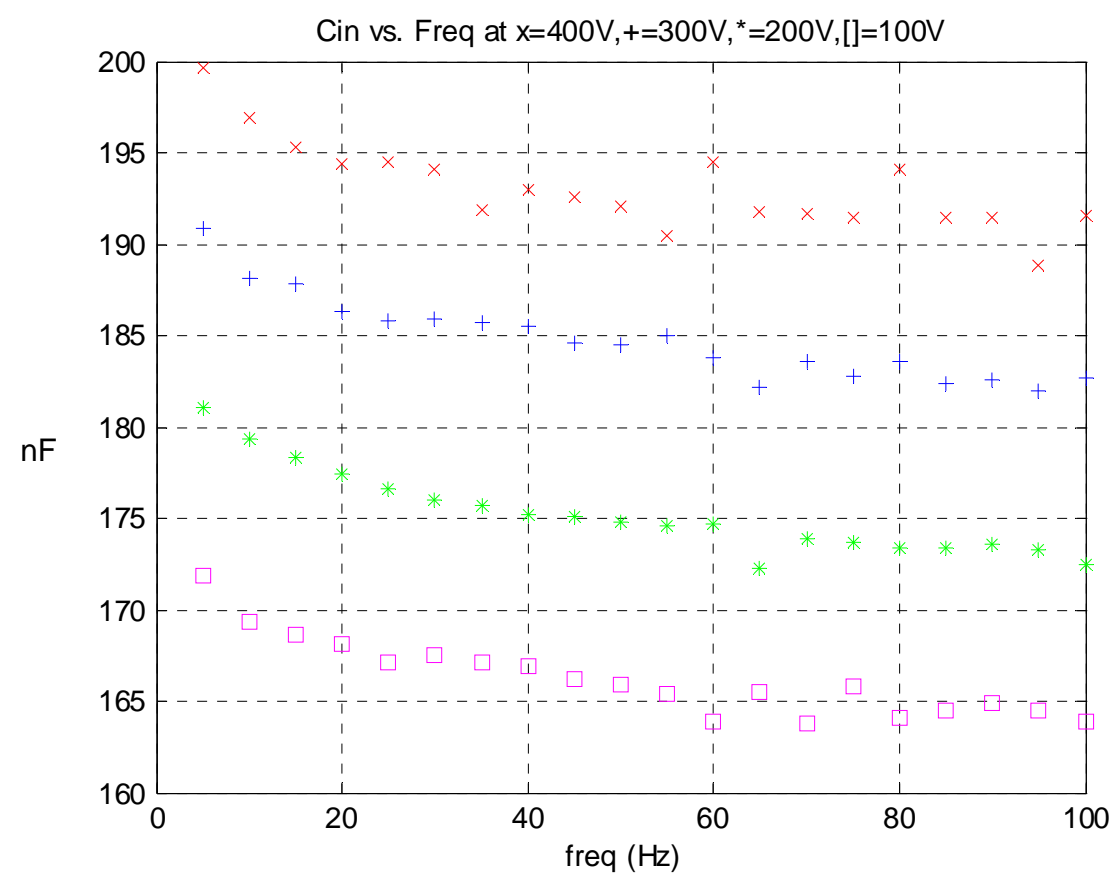

Fig. 25. No load input capacitance as a function of frequency.

\subsection{PUMP PERFORMANCE}

ORNL has developed a novel hydraulic pump/actuator test bed (see Fig. 26), building upon the central idea of a distributive passive valving (see Fig. 27) scheme to achieve very high frequencies in moving small drops of fluid rapidly in and out of the pumping chamber.

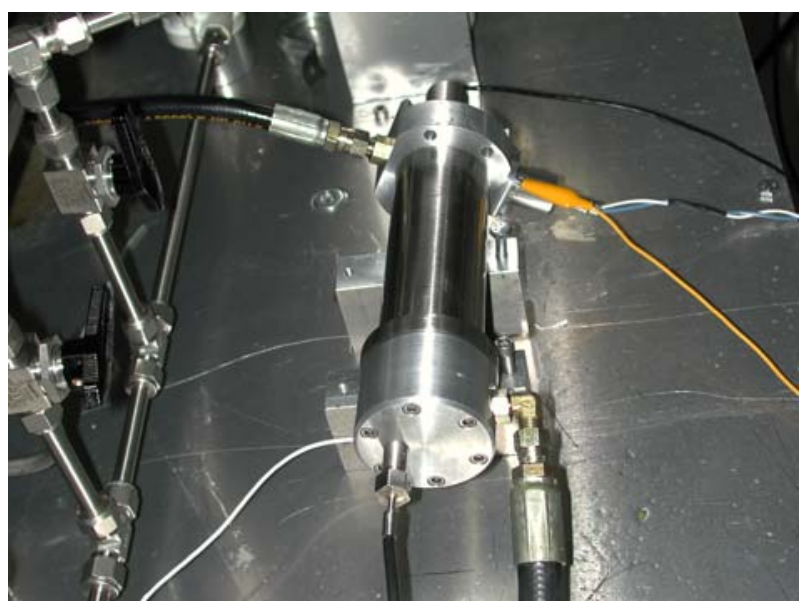

Fig. 26. ORNL's piezoelectric pump.

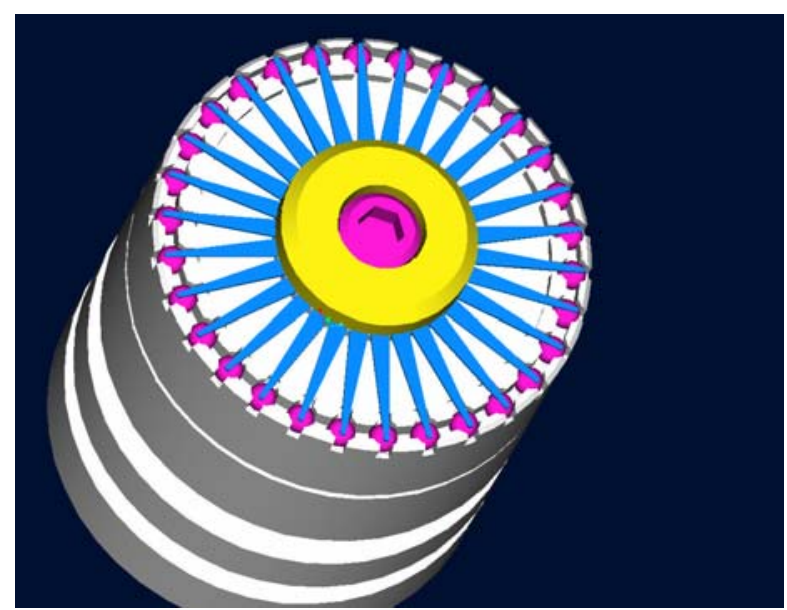

Fig. 27. Distributive valves.

As mentioned in Section 5, ball check valves have been installed on the piston and outlet port side of the piezoelectric pump. These ball valves have significantly reduced the leakage flows compared to a former design with just the flapper valves but without the ball checks. The design challenge is that these valves have to respond quickly (over $1 \mathrm{kHz}$ ) and have to operate over billion of cycles while meeting very tight mechanical tolerances. 
Due to power supply current limitations, the operational frequency that the stack can be driven is below $400 \mathrm{~Hz}$. For the final system, frequencies around $1 \mathrm{kHz}$ are required. The following results, which benchmark the performance of ORNL's piezoelectric pump, will have to be linearly scaled to evaluate the overall performance potential of the pump. The first measurement is for no load flow test, where the test fluid is pumped into a fixed volume for 100 seconds. The theoretical (based on computer simulation) and the measured flows are shown in Fig. 28. Approximately, 60\% volumetric efficiency from ideal (see Eq. (57)) at frequencies below $300 \mathrm{~Hz}$ was achieved. It is apparent from Fig. 28 that significant leakage flows still exist. Ball check valves on the piston and outlet port side have significantly reduced the leakage flows from the previous design of just the flapper valves without the ball checks. At higher frequencies (above $300 \mathrm{~Hz}$ ), the results (Fig. 28) suggest that the flappers are deviate significantly from the simulated values. Next, the deadhead pressure was tested by blocking the piston outlet flow. Theoretical pressures should exceed 1000 psi over a much larger frequency band than those shown in Fig. 29 (based on the assumed structural compliance and fluid bulk modulus values).

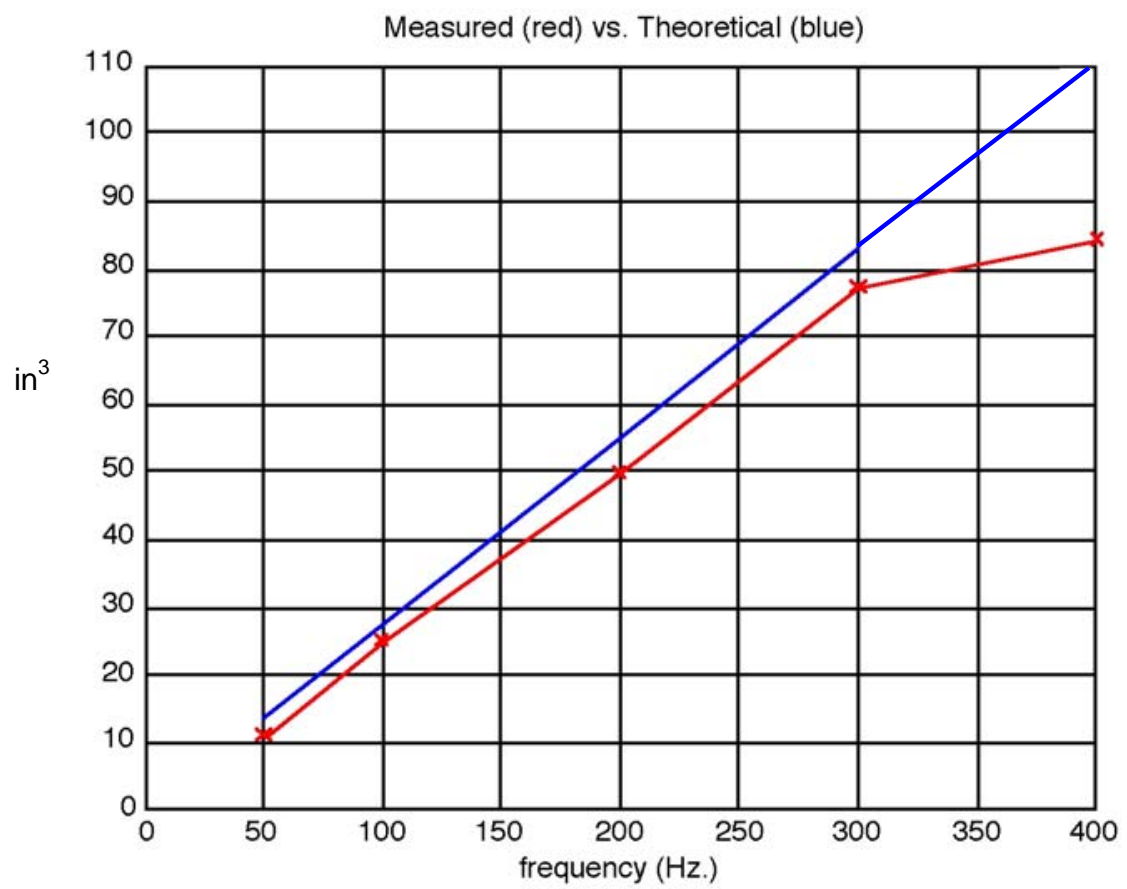

Fig. 28. Pump flow (theoretical - blue or top line; actual - red or bottom line).

There are two possible explanations for the discrepancies from the theoretical values: leakage or air that has not been properly evacuated and has remained entrained into the working fluid. Finally, the power produced by our pump should be around $200 \mathrm{~W}$ at $500 \mathrm{~Hz}$ and should scale linearly at lower frequencies. At $300 \mathrm{~Hz}$, the power should be around $120 \mathrm{~W}(300 \mathrm{~Hz}$ x $200 \mathrm{~W} / 500 \mathrm{~Hz})$. Figure 30 shows the results of a power test we have performed at various stack operating frequencies. This test entailed having the pump move fluid against a constant back pressure. As can be seen, we are roughly off by a factor of 5 from the expected value (i.e., roughly $23 \mathrm{~W}$ at $300 \mathrm{~Hz}$ compared with the theoretical expected $120 \mathrm{~W}$ ). Again, we are significantly below the theoretical value. There are two possible explanations: leakage and/or air that has not been properly evacuated or entrained into the working fluid or the distributive valves are leaking. However, the computer simulations which includes the nonlinear dynamics ignored in the sizing calculations are very close to the measured power values. In the computer simulation, significant fluid leakage around the valves is occurring. 


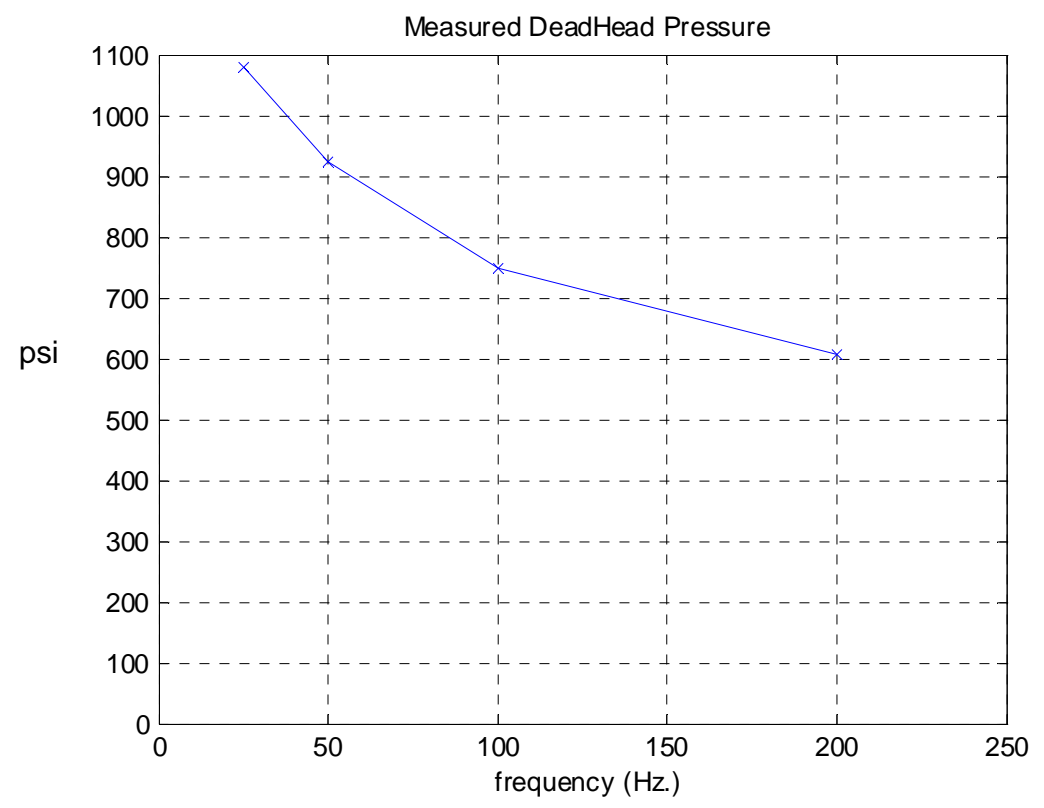

Fig. 29. Deadhead pressure versus stack frequency.

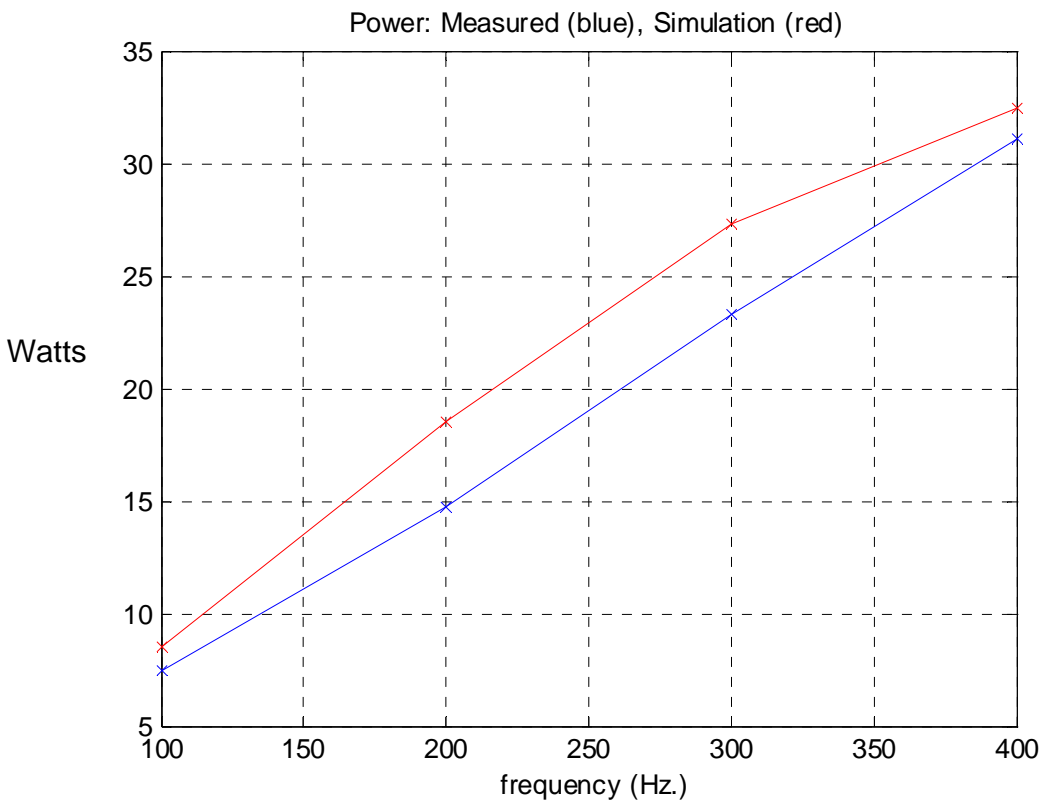

Fig. 30. Power out of the piezoelectric pump for load of $650 \mathrm{psi}$ and reservoir pressure of 50 psi. (Red or top curve is the simulation results and the blue or bottom curve is the actual or measured values.) 
Figures 31 and 32 show the simulation and measured flapper displacement inside the pumping chamber.

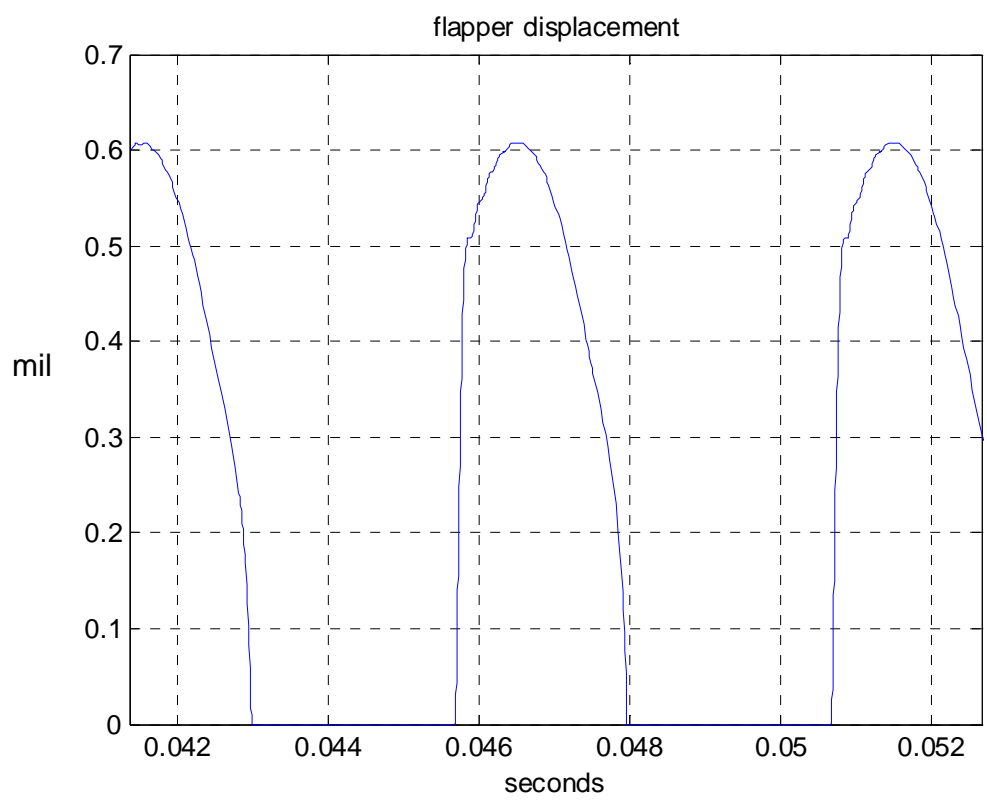

Fig. 31. Simulation of flapper motion $(200 \mathrm{~Hz})$.

Flapper displacement varied greatly: significantly more than shown in the Fig. 32 . Note that the flapper is not fully closing as in the simulation and appears to have a more square like peak than in the simulation.

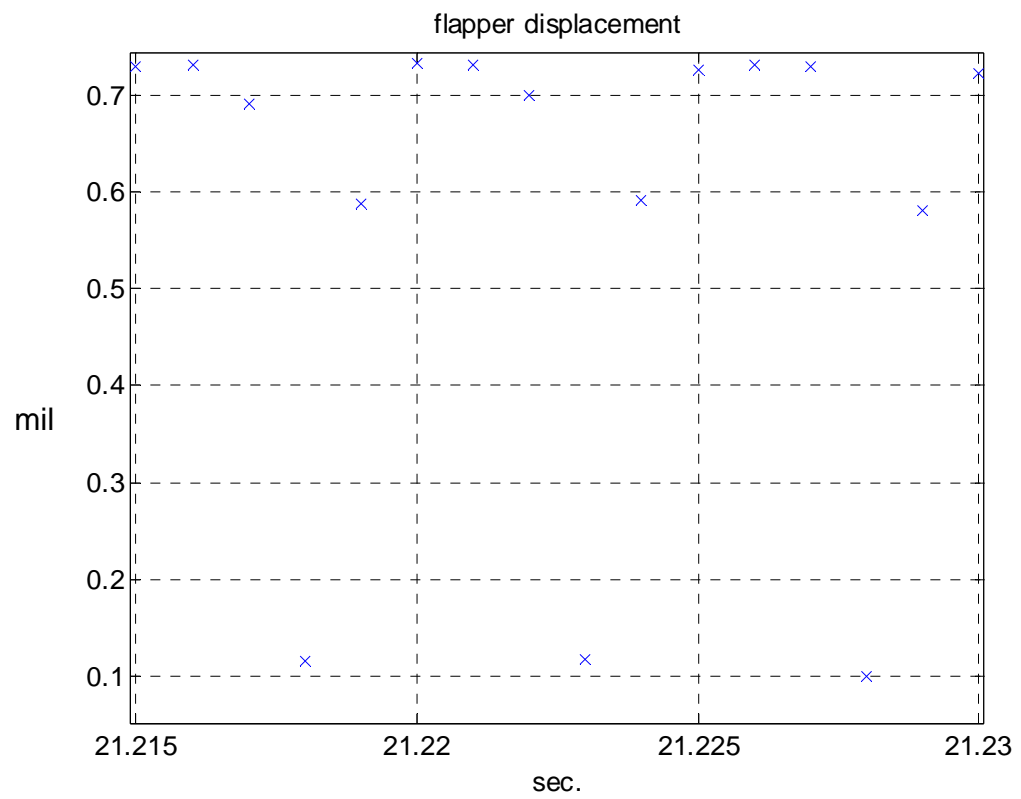

Fig. 32. Measured flapper displacement $(200 \mathrm{~Hz})$.

This observation supports the assertion that significant fluid is leaking past the distributive valves. 


\section{SUMMARY AND CONCLUSIONS}

This work addresses a new type of electric actuator that attempts to combine the best of both the electric and hydraulic mediums. The goal of this work is to expand upon a novel actuator that has been developed at ORNL that has the potential to make single crystal materials a driving source for a new type of hydraulic actuator. While a single crystal stack that was suitable for this project was not commercially available, a conventional piezoelectric material was utilized which will allow a single crystal stack in the future to be directly substituted into the proposed actuator.

The primary objective of this new actuator is to exceed the current level of power and volume density of electric motors to a value similar to that of conventional hydraulics. Currently, the power-to-weight ratios of hydraulic actuators are around 5 times and the power-to-volume ratios are 10 to 20 times that of comparable electric motors. One difficulty of using piezoelectric material pertains to converting small displacements to large motion. The approach taken in this report is that of a piezoelectric hydraulic pump, where small quantities of fluid are moved at very high frequencies one drop at a time. Based on ORNL's previous work in this area, we have an experimental piezoelectric pumping system that feeds a conventional hydraulic actuator. Currently we have achieved power levels around $32 \mathrm{~W}$ and deadhead pressures of over 1,000 psi. However, we are still below the power and volume densities of conventional electric motors. The reason appears to be fluid leaking past the miniature distributive valves.

However, a number of significant events have been achieved in the design, fabrication and testing of a piezoelectric pump. The construction and testing of the pump where small volumes of trapped air had to be avoided provided significant insight into the potential manufacturability of such an actuator. Small drops of fluid have been shown to be controllable by means of miniature valves. Very responsive valves have been designed and tested. Understanding of the physics behind this novel pump has been undertaken and appears to match the trends predicted by computer simulations as compared to the actual measurement of the pump during different loading conditions. Models of the high speed valves, fluid dynamics and compression of the small pumping fluid volumes, overall structural compliance, and the piezoelectric stack mechanical and electrical models have been presented. Further, an initial step in the overall sizing in the design process has been developed that allows selection and basic design of the pump to be undertaken. If Eq. (52) is the ideal pump power output, it appears that we have reached about $20 \%$ of the ideal power out of our pumping system. Similar to conventional pumps where volumetric efficiencies must be included in the overall pump sizing, an overall pumping efficiency need to be included in a practical piezoelectric based pump. Overcoming these limitations in performance are the goals of future work in this area. 


\section{REFERENCES}

1. Anderson, B. W., The Analysis and Design of Pneumatic Systems, Krieger Publishing Co., Malabar, Florida, 1967.

2. Standards Committee of the IEEE Ultrasonics, Ferroelectrics, and Frequency Control Society, 1987, Std. 176-1987.

3. Blevins, R. D., Formulas for Natural Frequency and Mode Shape, Krieger Pub. Co., Malabar, Florida, 1995.

4. Goldfarb, M. and N. Celanovic, "A Lumped Parameter Electromechanical Model for Describing the Nonlinear Behavior of Piezoelectric Actuators," Journal of Dynamic Systems, Measurement, and Control 119, 478-485 (1997).

5. Mason, W. P., Electromechanical Transducers and Wave Filters, D. Van Nostrand Co., New York, $2^{\text {nd }}$ edition, 1948.

6. Merritt, H. E., Hydraulic Control Systems, John Wiley and Sons, New York, 1967.

7. Nasser, K., D., J. Leo, and H. H. Cudney, “Compact Piezohydraulic Actuation System," SPIE Paper Number 3991-41, 2000.

8. Park, S. E. and T. R. Shrout, "Characteristics of Relaxor-Based Piezoelectric Single Crystals for Ultrasonic Transducers," IEEE Transactions on Ultrasonics, Ferroelectrics, and Frequency Control 44(5), 1140-1146 (1997).

9. Young, W. C., Roark's Formulas for Stress and Strain, McGraw-Hill, Inc., New York, 1989. 


\section{APPENDIX 1. BASIC DERIVATIONS}

The classical low-frequency electromechanical piezoelectric model ${ }^{1}$ is shown in Fig. A1-1 (note that a dc voltage bias from the voltage source is not shown, but has a magnitude equal to the peak ac signal V). For maximum power transfer from the voltage source to the mechanical load $Z_{m}$, assuming the mechanical load can be modeled as a pure resistor (i.e., inertial loading is ignored), $Z_{m}$ must have the same magnitude of impedance as $\mathrm{C}_{2}$ element after being reflected through the transformer,

$$
\mathrm{Z}_{\mathrm{m}}=\mathrm{R}_{\mathrm{m}}=\frac{1}{\mathrm{~T}^{2} \omega \mathrm{C}_{2}} \text {. }
$$

The magnitude of the voltage drop across the load at the source side of the transformer will be $\mathrm{V} / \sqrt{2}$, which means that the maximum power transfer is $\mathrm{P}_{\text {out }}^{\max }=\frac{\mathrm{V}^{2} \omega \mathrm{C}_{2}}{4}$.

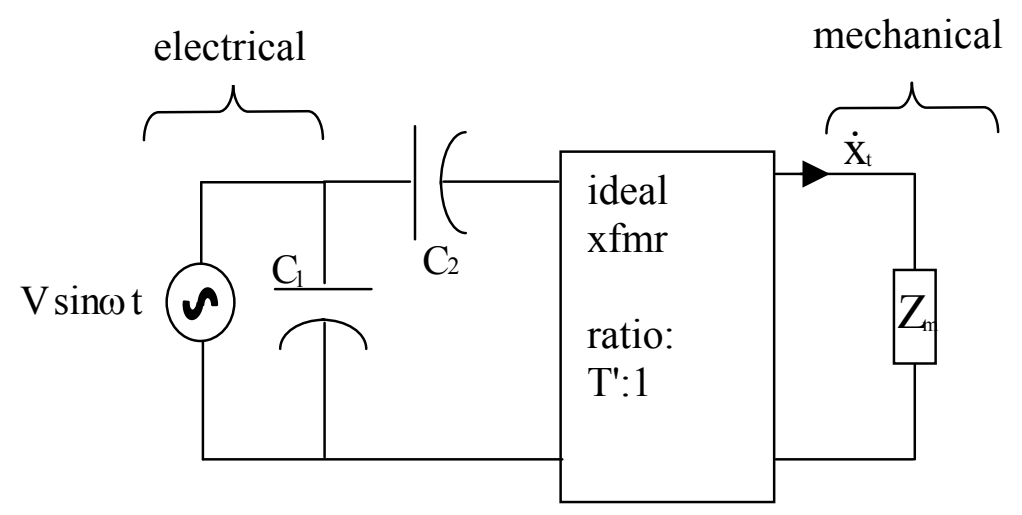

Fig. A1-1. Electromechanical model of piezoelectric stack and mechanical load.

Since only half the power is actually transmitted during each pumping cycle, the actual maximum power transfer would be

$$
\mathrm{P}_{\mathrm{out}}^{\max }=\frac{\mathrm{V}^{2} \omega \mathrm{C}_{2}}{8}
$$

The constituent equations for $\mathrm{C}_{2}$ is

$$
\mathrm{C}_{2}=\mathrm{k}^{2} \frac{\varepsilon_{33}^{\mathrm{T}} \text { Volume }}{\mathrm{t}^{2}}
$$

where

$\varepsilon_{33}^{\mathrm{T}}=$ electric permittivity,

$\mathrm{t}=$ electrode thickness,

Volume $=$ volume of piezoelectric stack, and

$\mathrm{k}^{2}=$ electrical to mechanical conversion constant $(0.75$ for PZN).

\footnotetext{
${ }^{1}$ Mason, W. P., Electromechanical Transducers and Wave Filters, D. Van Nostrand Company, New York, 1948.
} 
Next, substitute Eq. (A1-2) into Eq. (A1-1) utilizing, the definition of an electric field $E=V / t$ and $\omega=2 \pi \mathrm{f}$, Eq. (A1-1) becomes

$$
\mathrm{P}_{\mathrm{out}}^{\max }=\frac{\pi}{8}\left(0.5 \varepsilon_{33}^{\mathrm{T}} \mathrm{E}_{\max }^{2}\right) \mathrm{fk}^{2} \text { Volume }
$$

where $\mathrm{E}_{\max }$ is the maximum practical electric field (normally around $10^{6} \mathrm{~V} / \mathrm{m}$ which includes the dc offset). The magnitude of the force on the load side of the transformer (i.e., the primary voltage reflected to the secondary) is

$$
\mathrm{F}_{\mathrm{m}}=\frac{\mathrm{V}}{\mathrm{T}^{\prime} \sqrt{2}}
$$

Assuming that the stack and pumping chamber have the same cross-sectional area, A, the maximum pressure at maximum power transfer is

$$
\mathrm{P}_{\mathrm{m}}=\frac{\mathrm{V}}{\mathrm{T}^{\prime} \mathrm{A} \sqrt{2}}
$$

Substituting the constituent transformer ratio $T^{\prime}=s_{33}^{E} t / d_{33} A$ into Eq. A1-4,

$$
P_{m}=\left(\frac{V}{t}\right) \frac{d_{33}}{\sqrt{2} s_{33}^{E}}=\frac{E_{m a x} d_{33}}{\sqrt{2} s_{33}^{E}}
$$

where $\mathrm{P}_{\mathrm{m}}$ is the peak-to-peak pressure at maximum power transfer.

Finally, the magnitude of the peak displacement velocity $\dot{\mathrm{x}}_{\mathrm{T}}^{\max }$ at maximum power transfer is

$$
\dot{\mathrm{x}}_{\mathrm{T}}^{\max }=\frac{\omega \mathrm{C}_{2} \mathrm{~V}}{\sqrt{2}} \mathrm{~T}^{\prime}=\frac{\sqrt{2} \pi \mathrm{f} \mathrm{Ld}_{33} \mathrm{E}_{\max }}{2}
$$

where the defining relationships for $T^{\prime}$ and $C_{2}$ have been substituted into Eq. (A1-6) where $\mathrm{L}$ is the length of the piezoelectric stack. The maximum flow, $\mathrm{Q}^{\max }$, is equal to the peak displacement velocity time the chamber area, A, i.e.,

$$
\mathrm{Q}^{\max }=\frac{\pi \mathrm{fL} \mathrm{d}_{33} \mathrm{~A} \mathrm{E}_{\max }}{\sqrt{2}}
$$

and the average flow, $\mathrm{Q}^{\mathrm{avg}}$, is 


$$
\mathrm{Q}^{\mathrm{avg}}=\frac{\mathrm{fLd}_{33} \mathrm{AE}_{\text {max }}}{\sqrt{2}}
$$

The following table summarizes the previous results:

\begin{tabular}{|c|c|}
\hline Description & Governing relationship \\
\hline Maximum power transfer & $\mathrm{P}_{\text {out }}^{\max }=\frac{\pi}{8}\left(0.5 \varepsilon_{33}^{\mathrm{T}} \mathrm{E}_{\max }^{2}\right) \mathrm{f} \mathrm{k}^{2}$ Volume \\
\hline Pressure at maximum power transfer & $P_{m}=\frac{E_{\max } d_{33}}{\sqrt{2} s_{33}^{E}}$ \\
\hline Peak flow at maximum power transfer & $\mathrm{Q}^{\max }=\frac{\pi \mathrm{fL} \mathrm{d}_{33} \mathrm{~A} \mathrm{E}_{\max }}{\sqrt{2}}$ \\
\hline Average flow at maximum power transfer & $\mathrm{Q}^{\mathrm{avg}}=\frac{\mathrm{fL} \mathrm{d}_{33} \mathrm{~A} \mathrm{E}_{\text {max }}}{\sqrt{2}}$ \\
\hline
\end{tabular}




\section{APPENDIX 2. FLUID COMPLIANCE}

How much will the fluid in a chamber, assuming a constant cross-sectional area, when subjected to a force change in lateral dimension? With a stroke length of $75 \mu \mathrm{m}$ and a fluid bulk modulus of 100,000 psi and from the definition of fluid bulk modulus, ${ }^{2}$ one can derive the following relationship:

$$
\Delta \mathrm{P}=-\beta \frac{\Delta \mathrm{V}}{\mathrm{V}}=-\beta \frac{\mathrm{AL}_{2}-\mathrm{AL}_{1}}{\mathrm{AL}_{1}}=\beta \frac{\mathrm{L}_{1}-\mathrm{L}_{2}}{\mathrm{~L}_{1}},
$$

where

$\beta=$ fluid bulk modulus,

$\Delta \mathrm{P}=$ change in pressure,

$\mathrm{L}_{1}, \mathrm{~L}_{2}=$ initial and final length,

$\mathrm{A}=$ cross-sectional area,

$\mathrm{V}=$ volume, and

$\Delta \mathrm{V}=$ change in volume.

Rearranging Eq. (A2-1), the change in length in the fluid chamber for a 2,000 psi of pressure is

$$
\mathrm{L}_{1}-\mathrm{L}_{2}=\mathrm{L}_{1} \frac{\Delta \mathrm{P}}{\beta}=75 \frac{2,000}{100,000}=1.5 \mu \mathrm{m} .
$$

${ }^{2}$ Merritt, H. E., 1967, Hydraulic Control Systems, John Wiley and Sons, New York. 
ORNL/TM-2003/188

\section{INTERNAL DISTRIBUTION}

1-5. J. B. Chesser

6. E. C. Fox

7. R. G. Gilliland

8-12. J. F. Jansen

13-17. R. F. Lind

18. P. D. Lloyd
19-23. L. J. Love

24-28. F. G. Pin

29. Central Research Library

30. ORNL Laboratory Records-RC

31-32. ORNL Laboratory Records-OSTI

\section{EXTERNAL DISTRIBUTION}

(This document was cleared by DARPA and has been approved for Public Release, Distribution Unlimited.)

33. Teresa Fryberger, Director, Environmental Remediation Sciences Division, SC-75/Germantown Building, U.S. Department of Energy, 1000 Independence Ave., S.W., Washington, DC 20585-1290

34. Mark Gilbertson, Director, Office of Basic and Applied Research, EM-52/Forrestal Building, U.S. Department of Energy, 1000 Independence Ave., S.W., Washigton, DC 2585

35. Roland Hirsch, SC-73/Germantown Building, U.S. Department of Energy, 1000 Independence Ave., S.W., Washington, DC 20585-1290

36. John A. Main, DARPA-DSO, 3701 N. Fairfax Dr., Arlington, VA 22202-1714

37. Ann Marie Phillips, Idaho National Engineering and Environmental Laboratory, Bechtel BWXT Idaho, LLC, P.O. Box 1625-3765, 2525 Fremont Ave., Idaho Falls, ID 83415-3765

38. Sylvia Wolfe, Oak Ridge Site Office Program Manager, U.S. Department of Energy, P.O. Box 2008, MS-6269, Oak Ridge, TN 37831-6269 